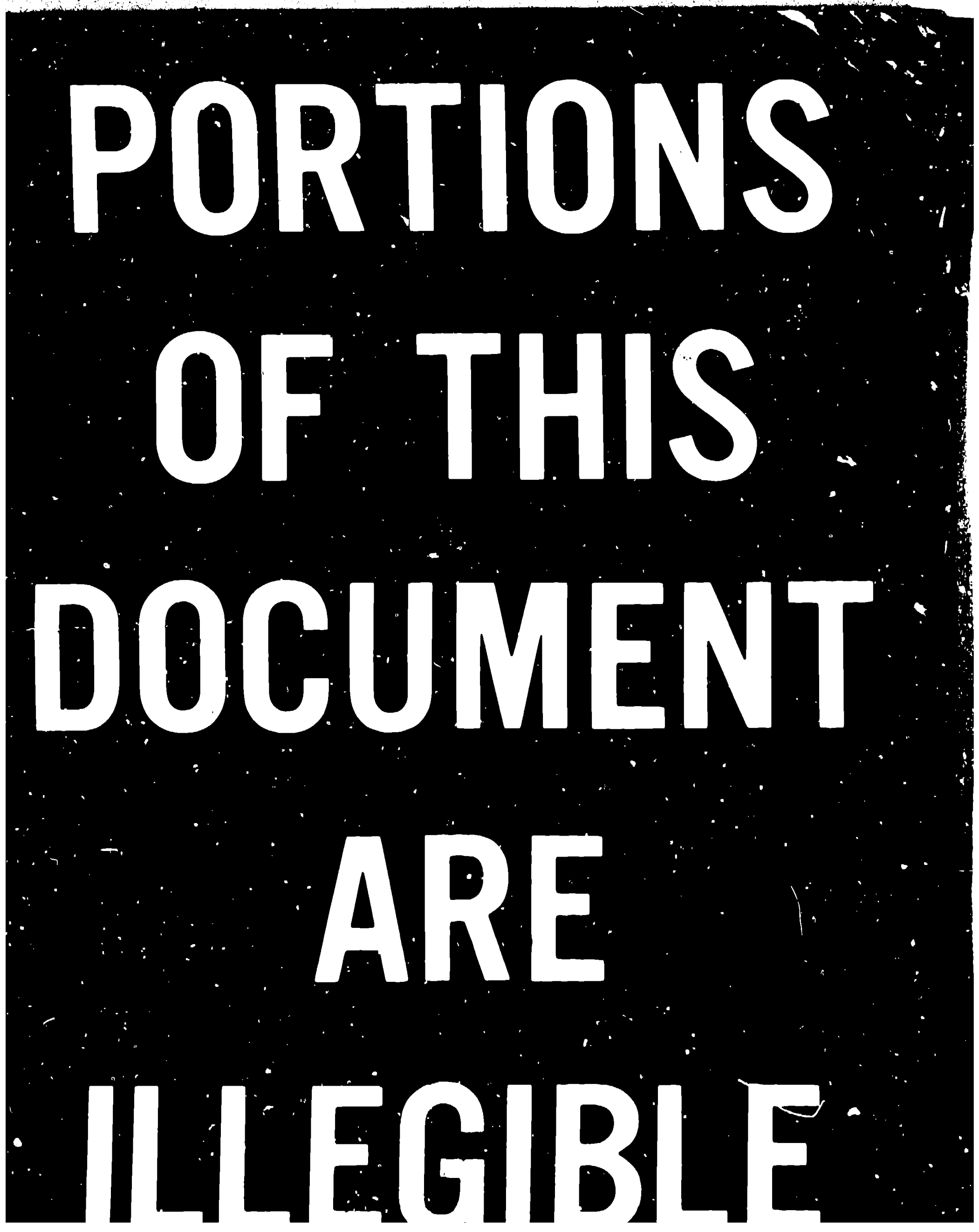




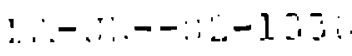

$$
\begin{aligned}
& \therefore: \because \quad 1: \because 1: \underline{1}
\end{aligned}
$$

TITLE: NEUTRON-ANTINEUTRON CONVERSION EXPERIMENTS

AUTHOR(S) llerbert l. Anderson

SUBmitted to Proceed Inf: of the Thlral Workshop on cirand linflicallom, April 15-17 i982, Unlve of North Ciarollnil, Chipel l1111. NC 27514

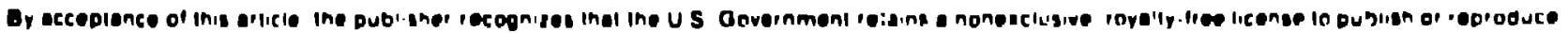




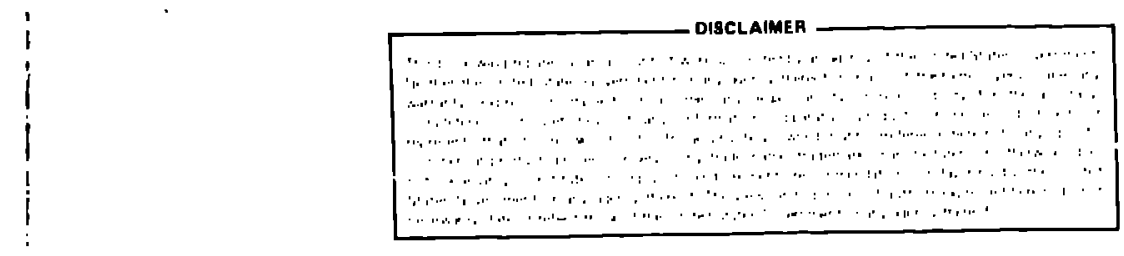

YELIRRN-AIIINEITRON_CONYERSION EYPERIYEXIS*

H. L. Anderson-

'1. Introduction

A great deal of actention has been given in this hivistail $h$ proton decay experiments. These experiments lwit for a viola: ia at baryon number $: B=1$, as predicted by Grand lnificu Theurjes. Ihur ate many experimerts searching for proton decay in deep rines ani lais-

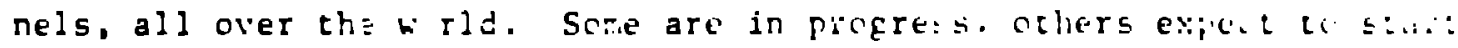

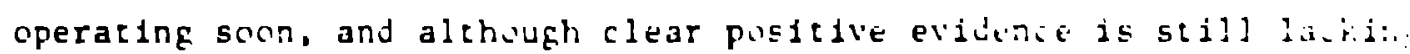

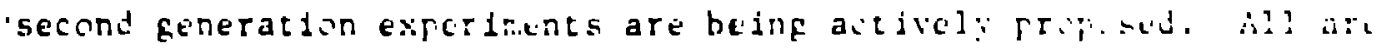

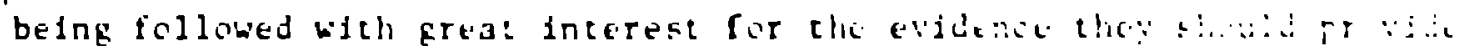
arout the valddty and the nature of thes tharien.

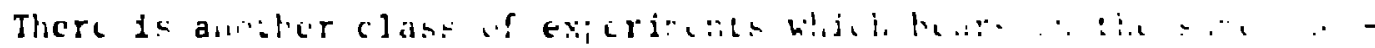

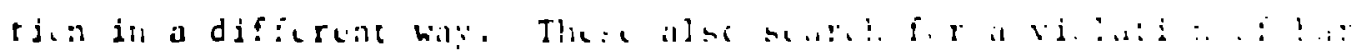

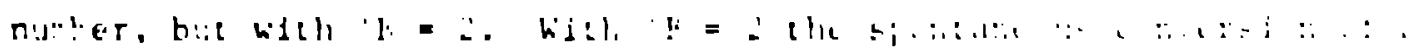

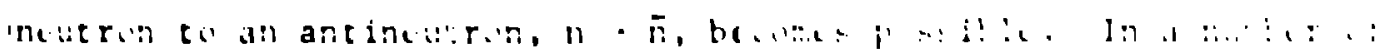

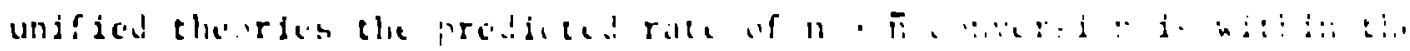

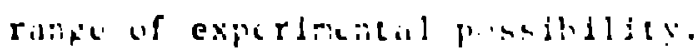

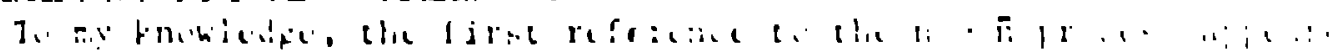

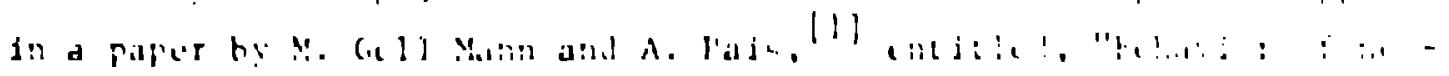

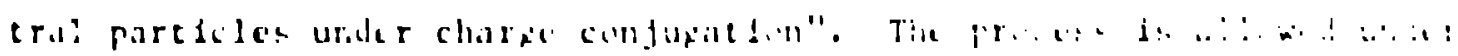

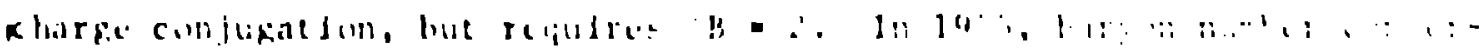

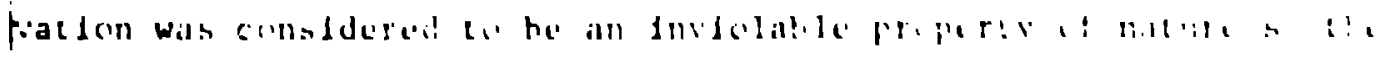

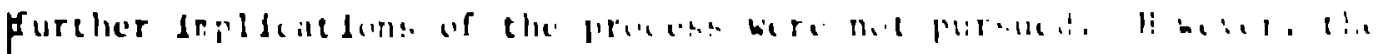

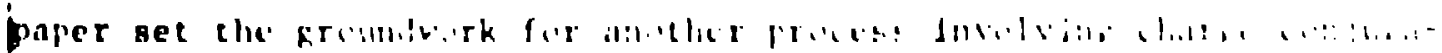

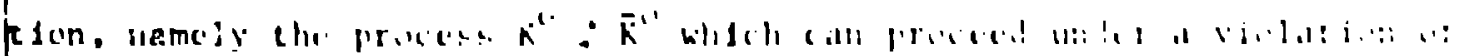

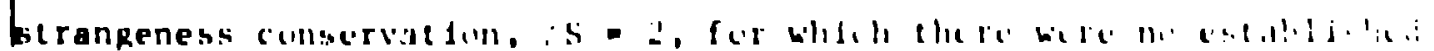

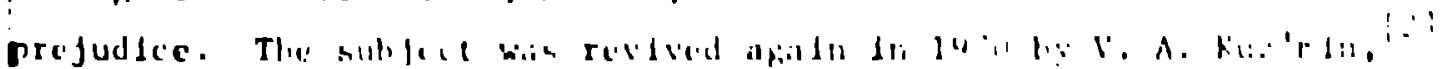

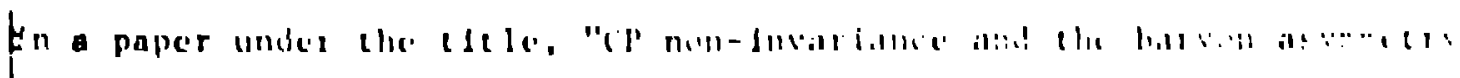

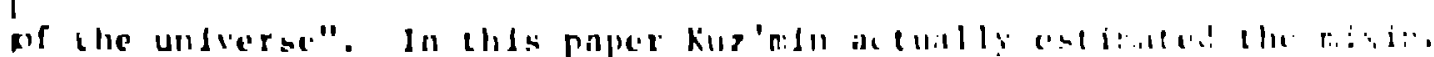

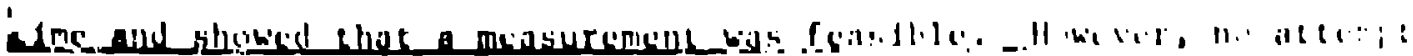

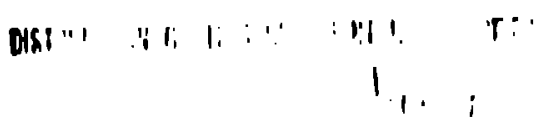


to carry out such an expertment was made. The experimentalists fot into the act after S. L. Glashow, T3] high priest of Grand lnificatiun.

launched his campalgn to emphasize the Importance and the chaljenjus of experiments that would provide a realistic basis for these idcas. For the $n \rightarrow \bar{n}$ process he proposed an excension of $5 !(5)$ with a 6-ferriun coupling that would allow the annthllation of 6 quarts, or altrinilive1y_the coṇversion. of 3 gugerks_inte. 3 ant 1-quarks. The diagrat fr this process is shown in Figure 1.

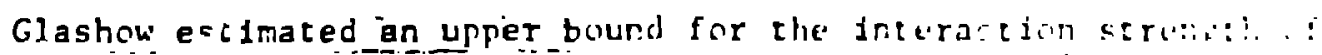
this coupling frow the lower bourd on nuelear stahility. $\{4,5\}$ Tha.

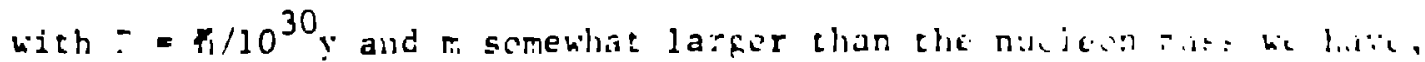

$$
r \cdot \bar{*} \cdot 10^{-2 \mathrm{i}} \text { ey. }
$$

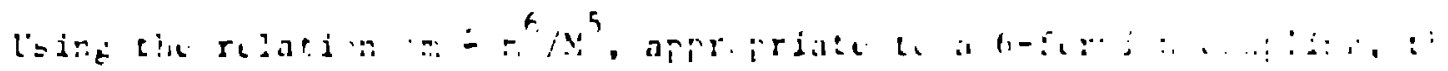

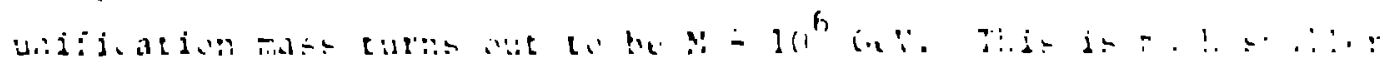

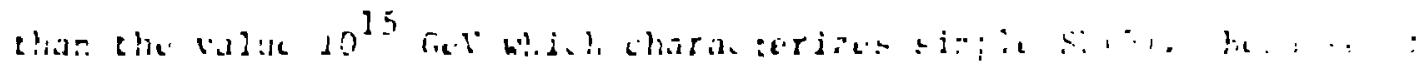

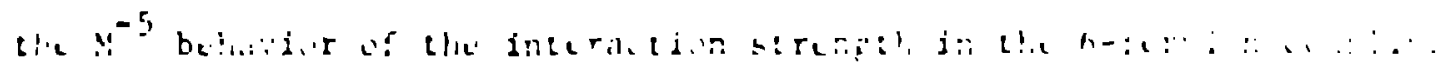

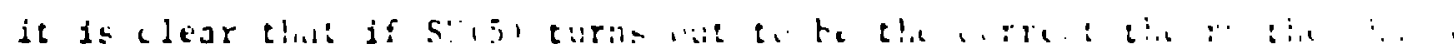

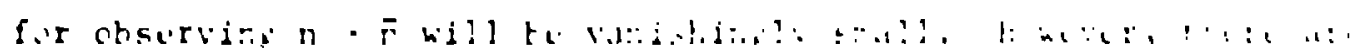

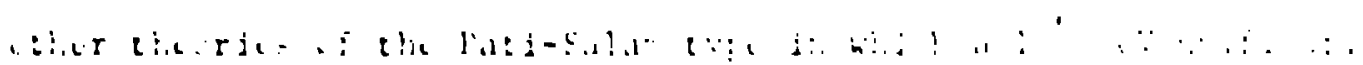

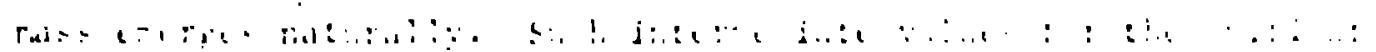

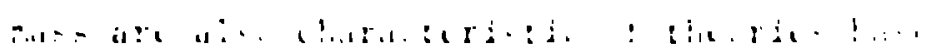

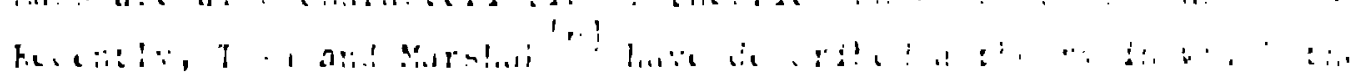

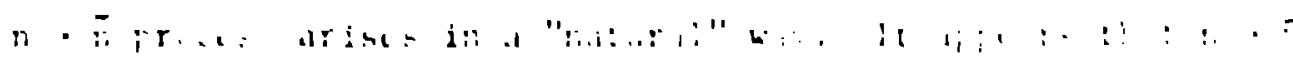

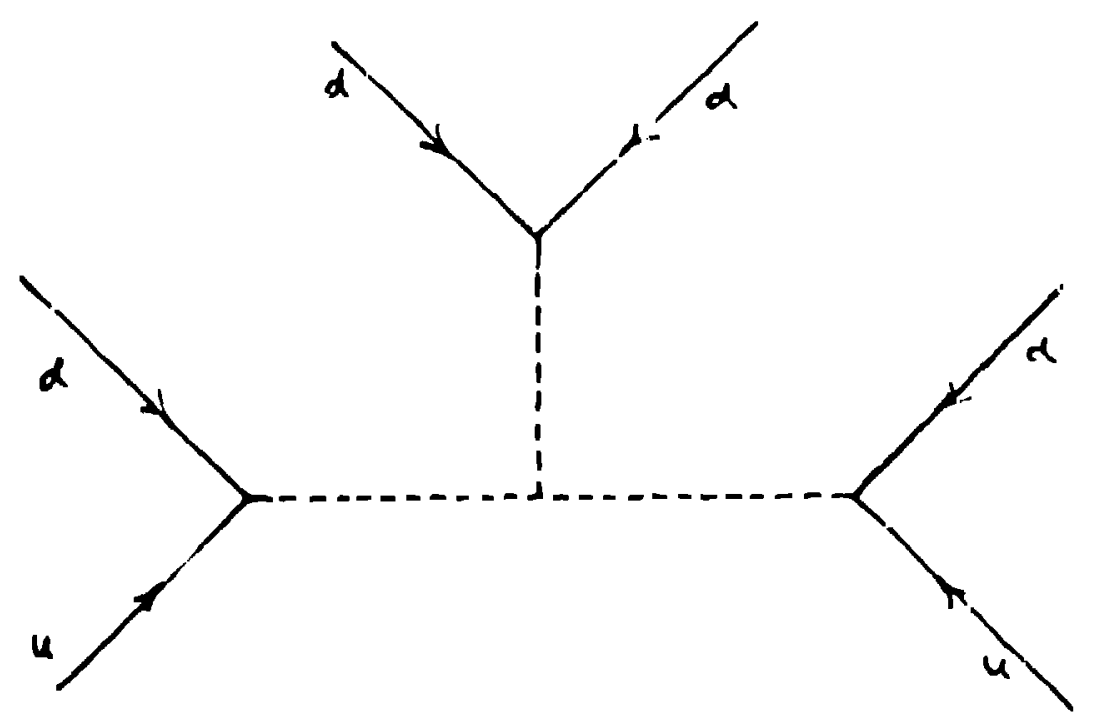

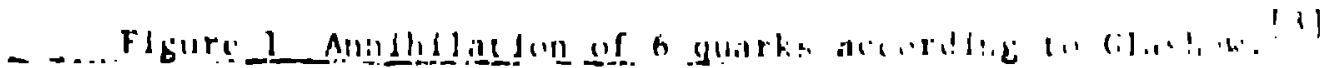




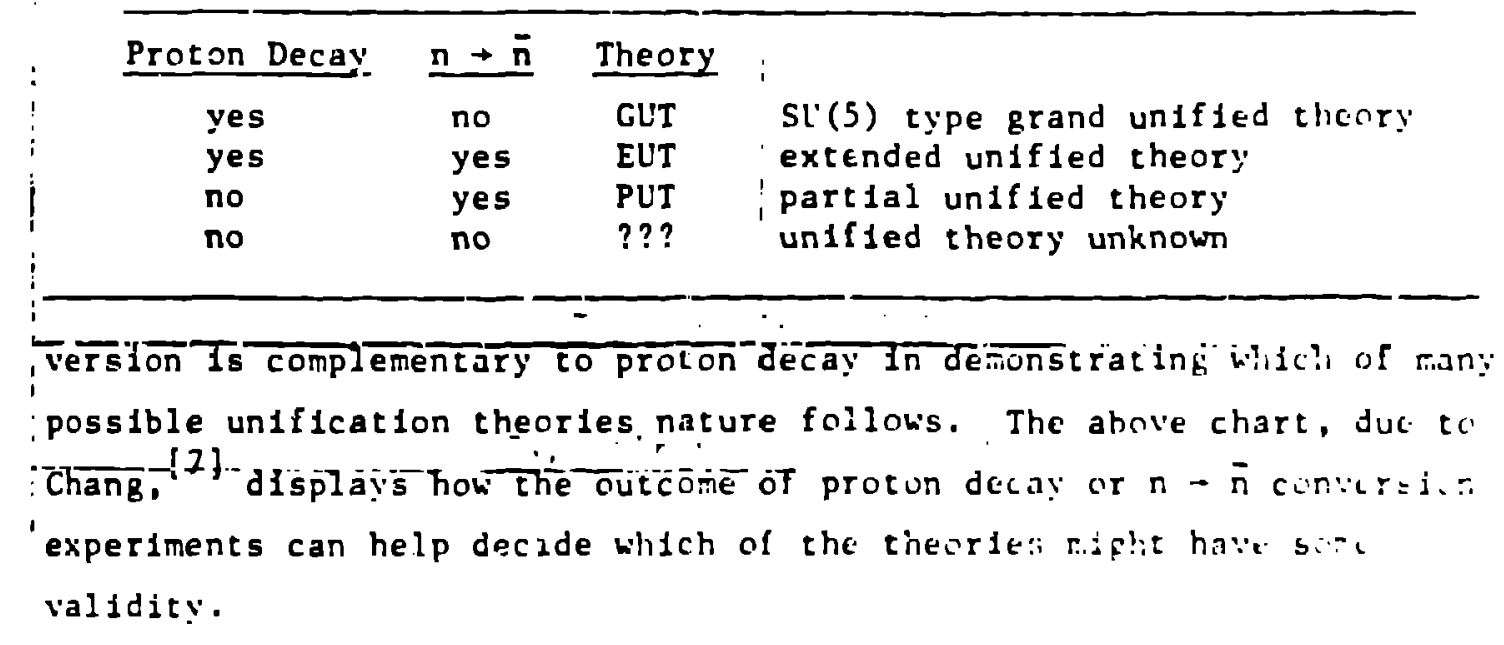

\section{Veutron-intineutron Conversion}

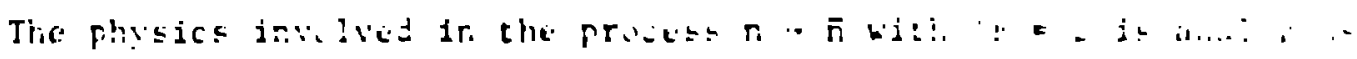

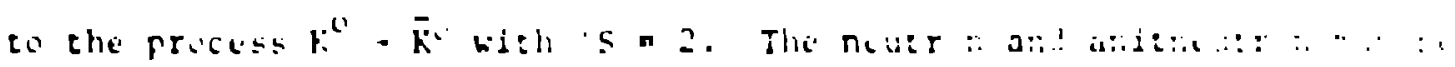

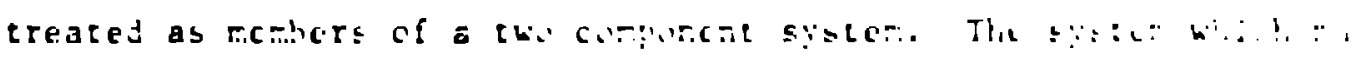

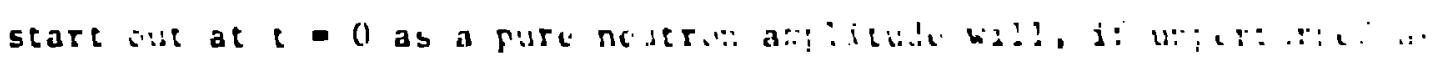

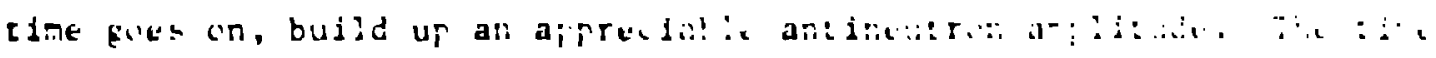

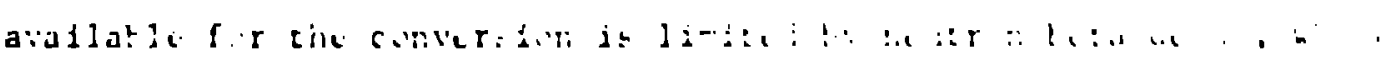

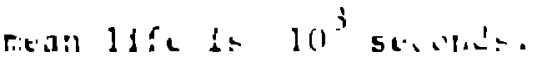

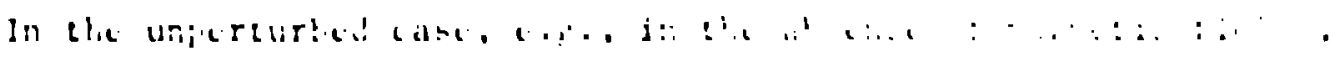

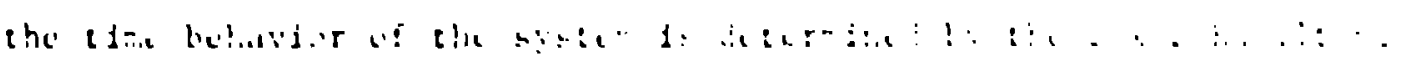
i.jerit.r.

$$
\left(\begin{array}{cc}
r & -1 \\
\because & 1
\end{array}\right)+\cdots
$$

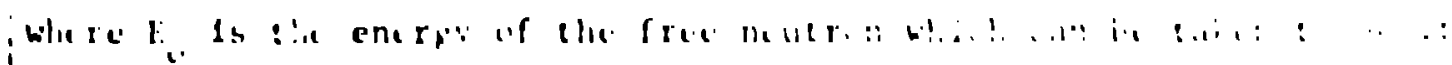

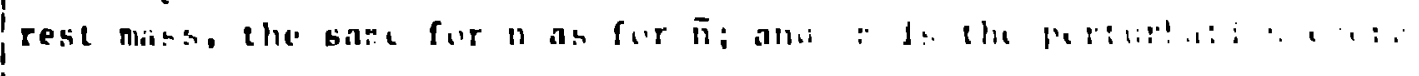

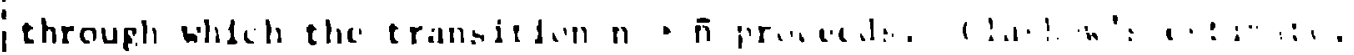

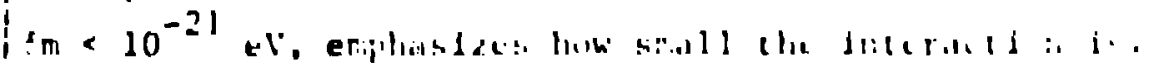

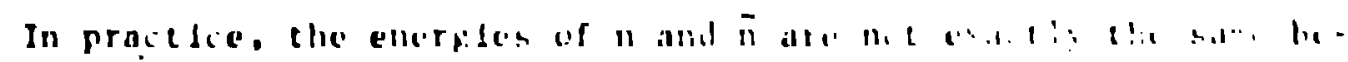

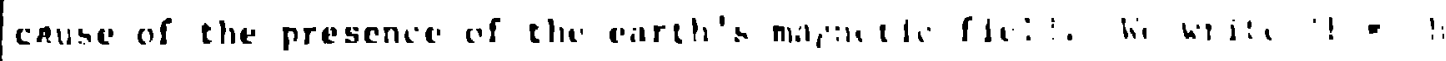

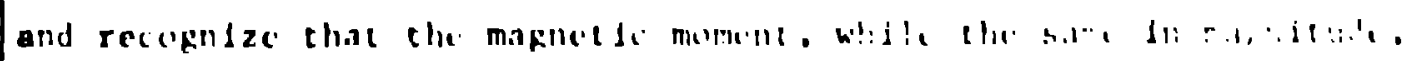

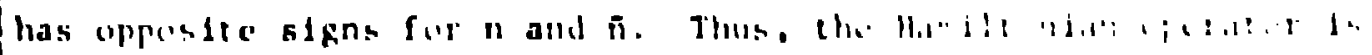
wr 1 ten 


$$
\left(\begin{array}{ll}
E_{0}+\Delta E & d m \\
f_{m} & E_{0}-L E
\end{array}\right) \cdot
$$

If an $n-\bar{n}$ mixing exists, neutrons and antineutrons are no lonfer eigenstates but can be expressed as a mixture of new eigenstates $n_{1}$ and $\mathrm{n}_{2}$,

$$
\begin{aligned}
& n=n_{1} \cos \theta+n_{2} \sin \vdots, \\
& n=-n_{1} \sin \vdots+n_{2} \cos :,
\end{aligned}
$$

with $\tan 2 \cdot- \pm m / \therefore E$.

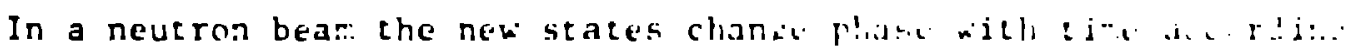

๘

$$
\begin{aligned}
& n_{1}(t)=n_{1}(0) \operatorname{exi}\left(-j \Gamma_{1}\left(t / q_{1}\right) .\right. \\
& n_{2}(t)=n_{2}(0) \exp \left(-j I_{2}(t / 4) .\right.
\end{aligned}
$$

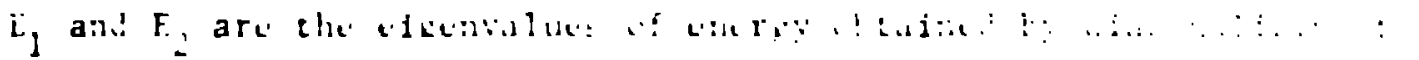
miatris,

$$
\begin{aligned}
& r_{1}=r_{1}+r^{2}+r^{2} !^{\prime} z \\
& r_{2}=r_{1}-\left(n^{2}+!^{\prime} !^{\prime} !\right.
\end{aligned}
$$

$17 x: \ldots$,

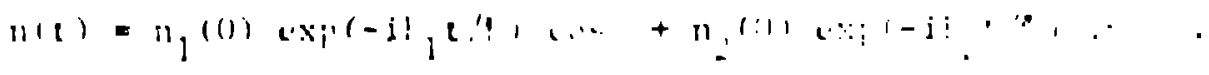

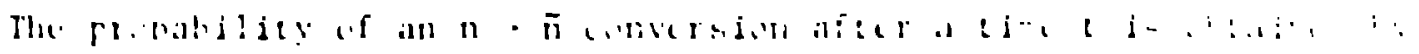

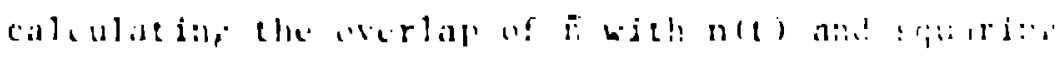

$$
P_{n}(x)=\cdot \bar{n} n(t)=:
$$

Whth the resitir

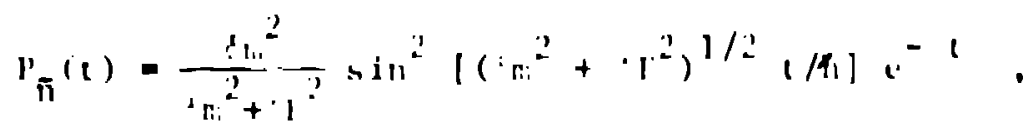

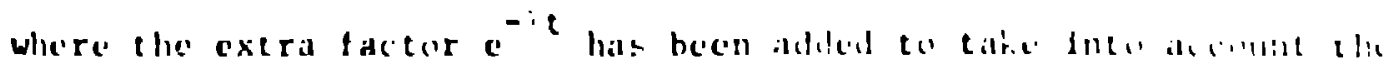
beta decny of the neitrin. 
Table 2 Number of events in a plausible experiment

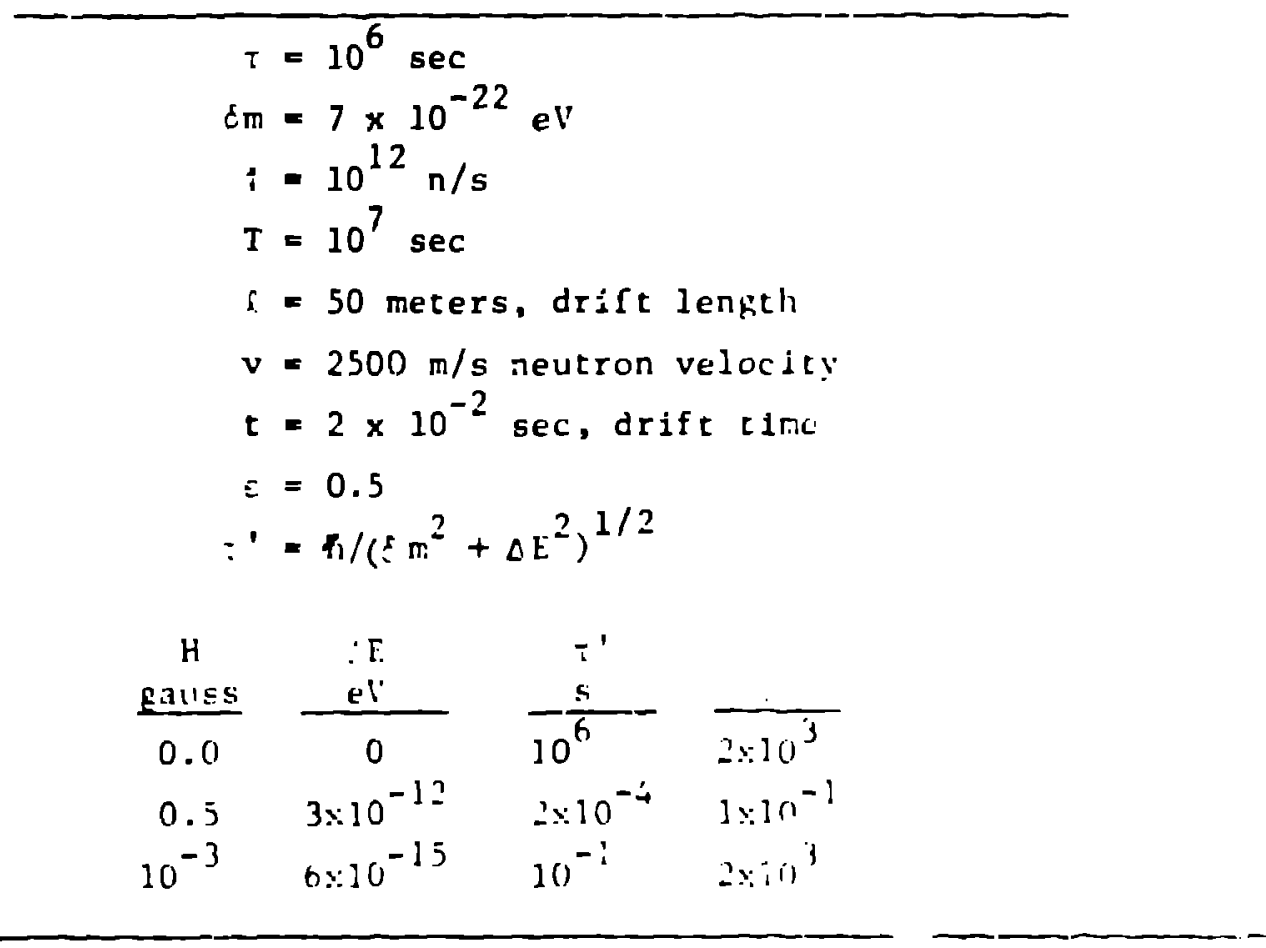

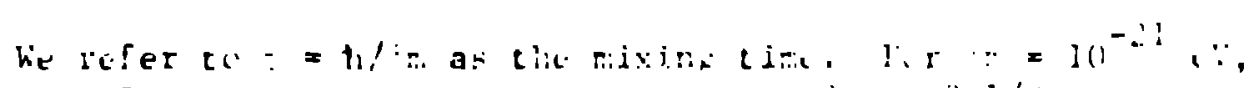

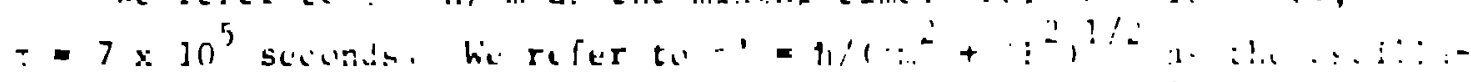

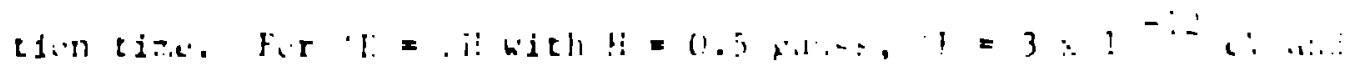
$z^{\prime}= \pm \mathrm{x} 10^{--}$scinisin.

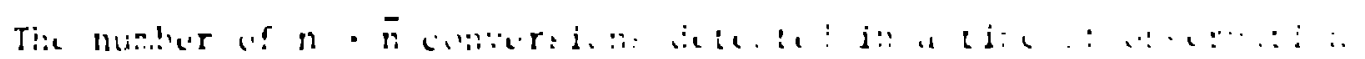
Tis.

$$
=I_{n}(1): T .
$$

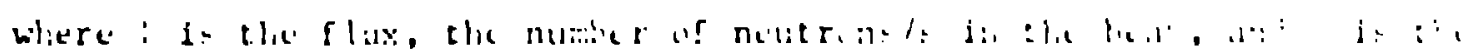

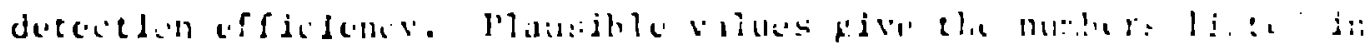
Table: :

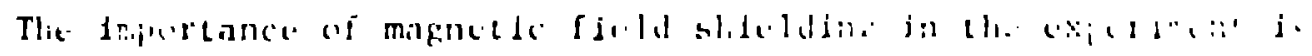

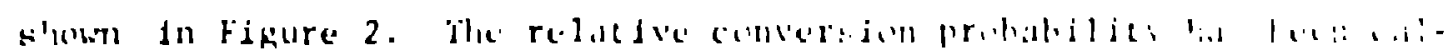

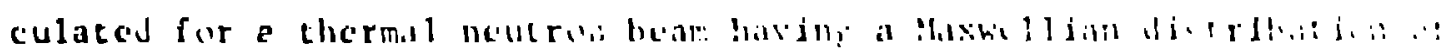

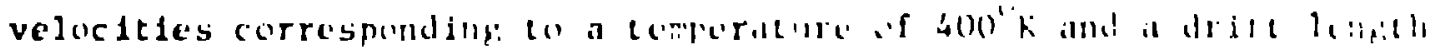

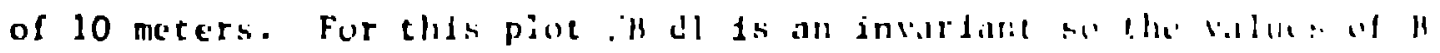

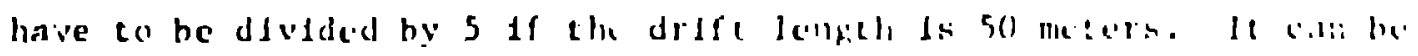

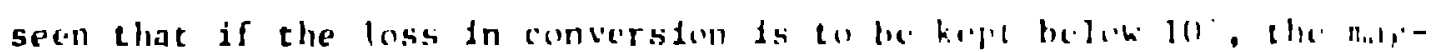
net1, fleld intensity must be kept belob $1.2 \times 10^{-3}$ fillus. Thi. requires a rather elaburate mu-metal shidel topetieg will current 


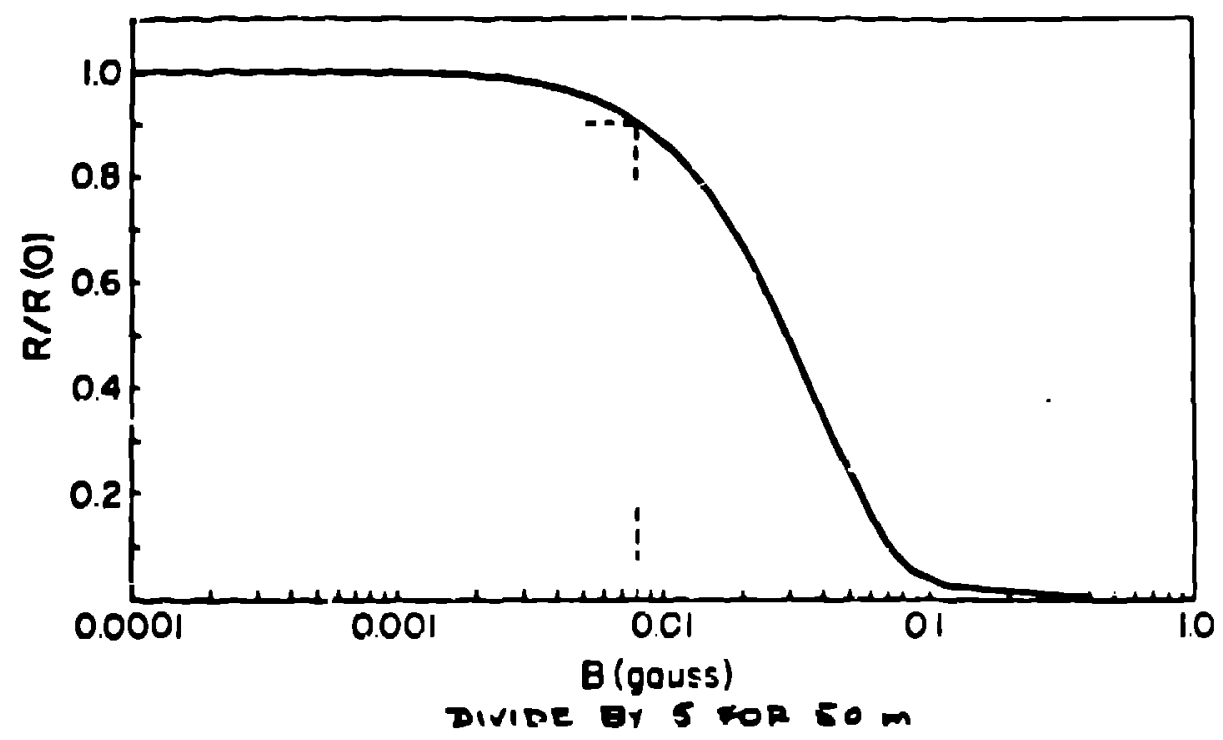

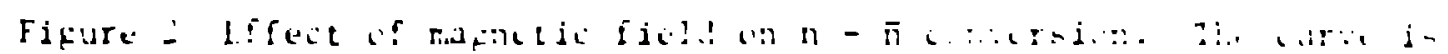

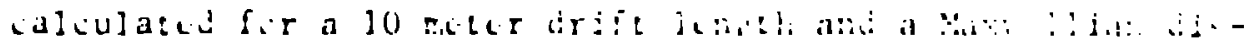

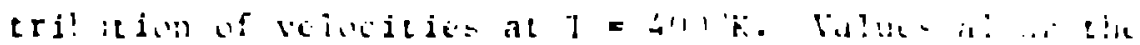

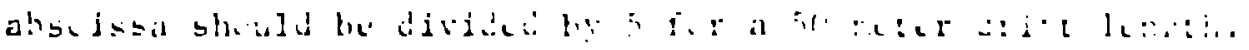

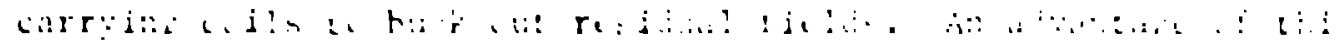

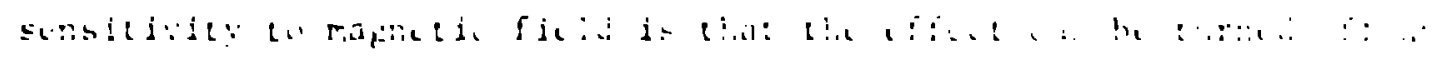

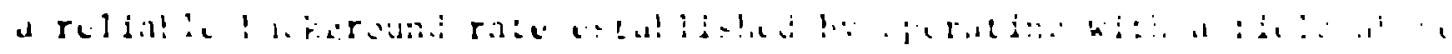
(). 1 pil'...

3. I:jeri*itil! i i*i:

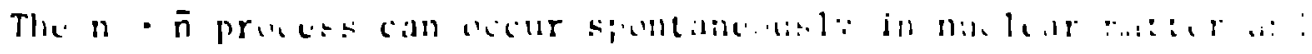

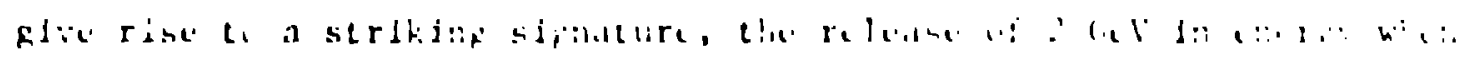

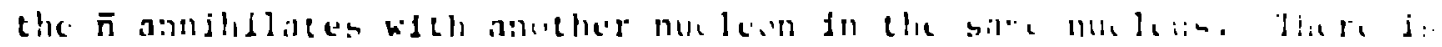

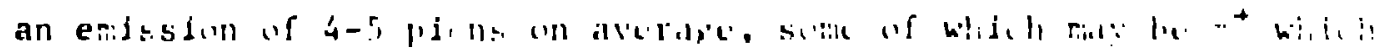

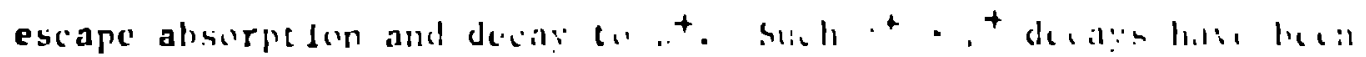

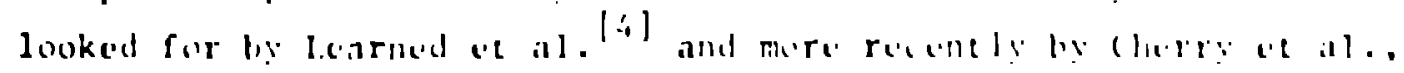

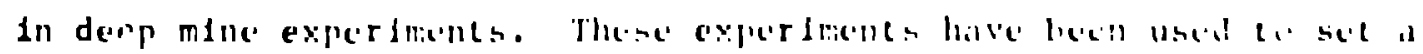

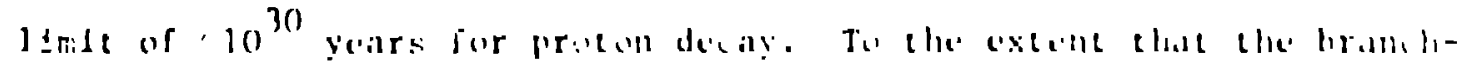

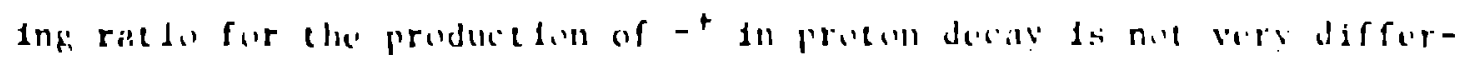

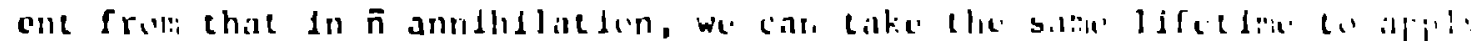

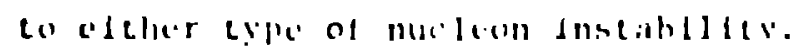

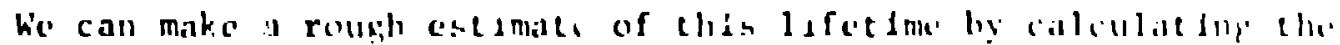


transition rate using Fermi's Golden Kula,

$$
\Gamma=\frac{2-}{h_{1}}|\mathrm{H}|^{2} \frac{\mathrm{dN}}{\mathrm{dE}}
$$

where the transition matrix element $H=\delta m x$ an overlap integra], and $\mathrm{dN} / \mathrm{dE}$ is the number of final states per unit energy interval. Lsing plausible values, a level spacing. $(\mathrm{dN} / \mathrm{dE})^{-1}=\mathrm{JeV}$, a mixing $t$ ! ine of $10^{6}$ seconds, and taking the overlap between two nucleons in a nucleus to be of the order of $10^{-2}$ (Mohapatra and Marshak [7] estimate), wit obtain $r^{-1}-7 \times 10^{29}$ years. Thus, an experiment on neutron-antineutron conversion that sets a mixing $t 1 \pi \mathrm{e}>10^{6}$ second ilmit for nucleon stability for this type of process.

various estimates of the mixing time based on the experinenta: limit for nucleon stability have appeared in the literature. ilthuri. the formulas obtained may be accurate enough, the results differ beatat the parameters are not so well $\mathrm{knhm}$. These estirates arc listed in Table 3 .

It appears that experiments with a sensitivil $\because:=10^{7} \mathrm{~b} . .12 \mathrm{~h}$. quite important. Because of the quadratic dependenit: $-i=2$, a

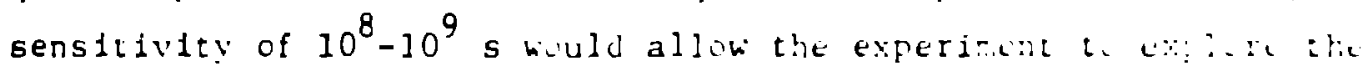

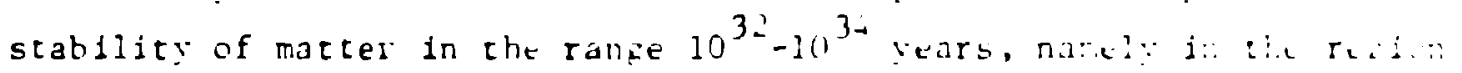

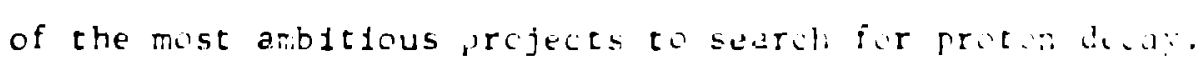

Table 3 Eatibates of riaing tirit

\begin{tabular}{|c|c|c|c|c|}
\hline \multirow[b]{2}{*}{ Ref. } & \multirow[b]{2}{*}{ lear } & \multirow[b]{2}{*}{ suther } & \multicolumn{2}{|c|}{$! i \cdot j:$} \\
\hline & & & $=-1$ & $n: 1=$ \\
\hline 2 & 1970 & '.A. Kuz'rian & - & ] $0^{4}: \therefore$ \\
\hline 3 & 1979 & S.L. Glashow & - & ]$\left(0^{\prime}-1 i^{\prime \prime}\right.$ \\
\hline 7 & 1980 & R.N. Muhapatra and R.F. Murshak & $10^{30} \times$ & $10^{\circ}$ \\
\hline 8 & 1980 & M.V. Kazarnorskit et al. & $10^{3(1} \div$ & $2 \times 10^{7}$ \\
\hline 9 & 1381 & k.G. Chetyrkin et al. & $3 \times 10^{30} y$ & $3: 11^{7}$ \\
\hline 10 & 1980 & P.G.H. Sandars & $10^{30} y$ & $1.8: 10^{7}$ \\
\hline 11 & 1981 & Riazudin & $10^{3 n} y$ & $3 \times 10^{6}$ \\
\hline 12 & 1980 & L.N. Chang and X.P. Chank & $10^{30} y$ & $10^{7}$ \\
\hline 13 & 1980 & R. Cowsik and S. Nussinov & $10^{31} y$ & $5 \times 30^{7}$ \\
\hline
\end{tabular}


4. The $n-\ddot{n}$ Conversion Experiment

To observe the conversion $n-\bar{n}$ we arrange to have a large number of neutrons moving as slowly as possible within a long evacuated drift space carefully shielded from magnetic fields. The interaction of $\bar{n}$ with the target produces a spectacular signature. The annihilation reaction $\bar{n}$ or $\bar{p}$ occurs in the nucleus with a high cross-section and results in the emission of $4-5$ plons on average, and the release of $2 \mathrm{GeV}$ in energy. However, to realize the full sensitivity needed in such an experiment, the utmost care must be taken in the desien of the detector so that it will distinguish, with a high degree of certaint: annihllation events from the costic ray background. The difficuli: comes from the fact that $1 \mathrm{f} l$ event is found after 1 year of runing, we want $n$ be sure it is an annthilation event and not caused b: one $n$ the $10^{11}$ cosmic ray's that have traversed the detector dierine this tire. Moreover, the detector must function almost perfectly in the presence of a large background of the cafture gamma rays that invaiahl: a pany slow neutrons.

5. Annihilation Events

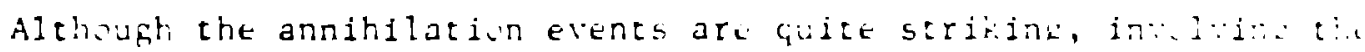
exiszion of $4-5$ pions on average, their eruge: is in the ratid of st:eral Mel, appreciably lower than the multi-cel fartilles that hid: energy experimentalists have becone accustomed to. The $r$ st r... if the

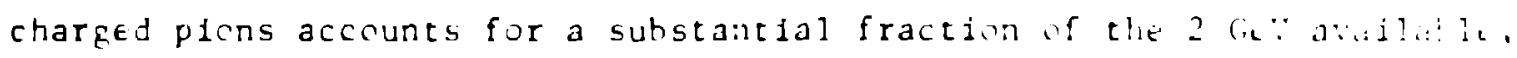
and since the projability of a nuclear irielaction is high, rish of the energ: goes into nuclear excltation and distntegratton. A Ewd duivil:

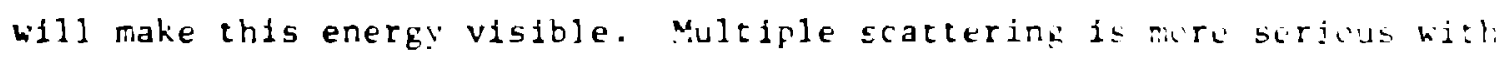
these low energy particles, making to more difficult to recoubrut the vertex.

The characteristics of the annihilation events arcknimn in conslderable detall from studies that have teen made $o^{\prime}$ ip annihilations a: rest. The branching ratios for the differeat modes i annihilation are given in Table $4 .[14]$ The difference in the case of $\bar{n}$ shuuld he minor because the same 1sotopic spin is involved in the initial state. In the case of np annthilation a different charge and lsoteple state is involved and some difference in the charge composition of the plons emitted can be expected. (15) The mean multiplicilics and energies of 
Table 4 Contribution of pionic states to pp annthilations at rest*

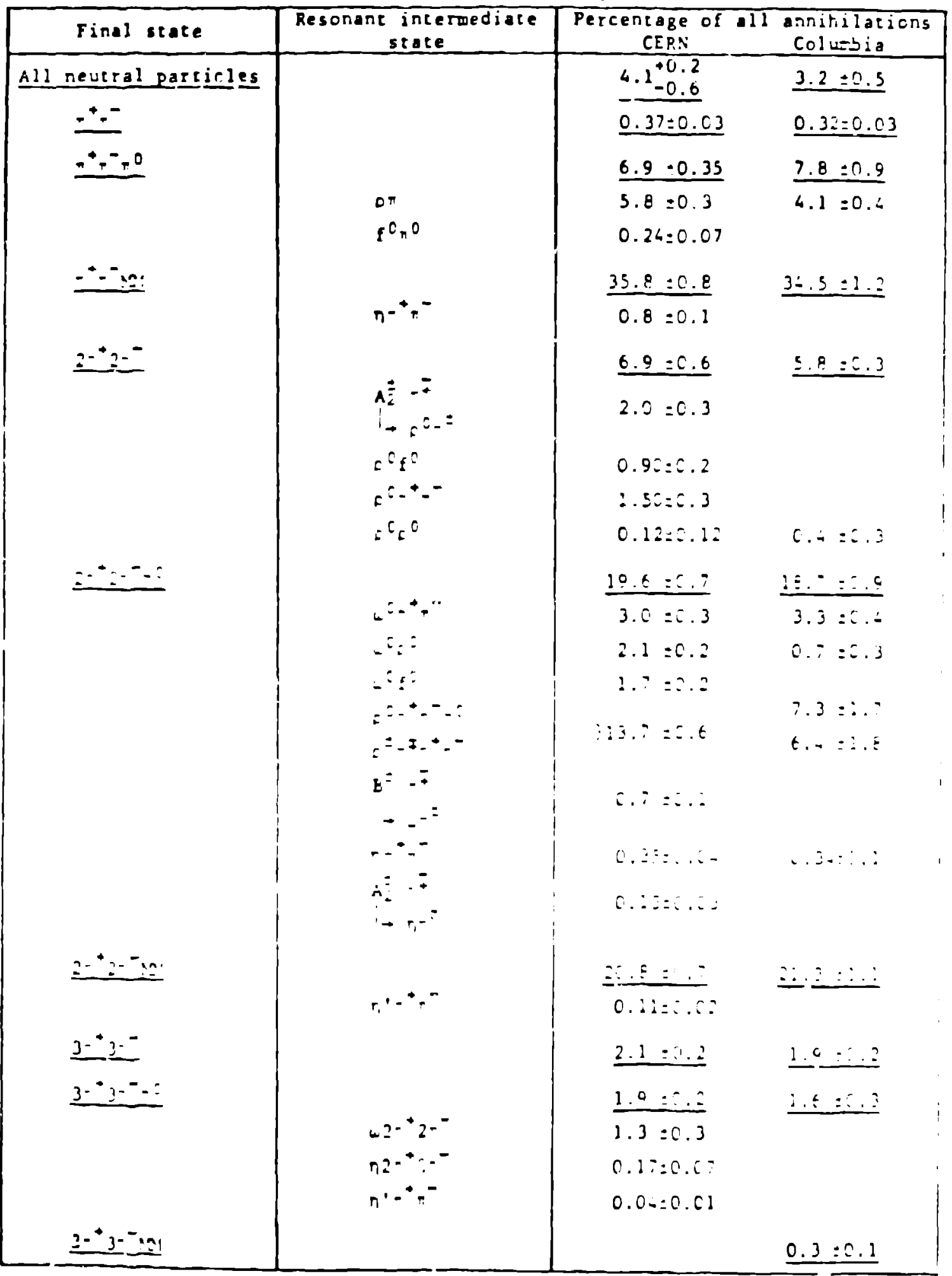

* This table updates the one publlshed by R. Armenteros and B. Frencli in High Energy Physics, Vol, 4 (Academlc Pruss,inc.), law lork, 190, witil data published later by the CERA-collége do rrance collahuration. In quoting percentapes for resonance production, no coract fons have hera made for decay modes not occurring in the given finil state. 
the pions for pp annihilations at rest according to a summary by Enstrom et a1. [16] are: $\left\langle\pi^{ \pm, 0}\right\rangle=5.02,\left\langle T^{ \pm}\right\rangle=3.06,\left\langle{ }^{-}\right\rangle=1.53$, and $\left\langle\mathrm{T}_{\pi}\right\rangle=234 \mathrm{MeV}$. The average number of charged pions according to Tab1e 4 is 2.95 .

It is important to note in Table 4 that there are very few - $+_{-}^{-}$ back to back events, only $0.35 \%$. This makes it plausible to trigger on a mintmum of three particles. To do this effectively, the trigger should be sensitive to the gammas from $\pi^{\circ}$. In the case of $\bar{p} p(\bar{n} n)$ annihilations, $3.6 \%$ have only -0 's. In $7.4 \%$ of the cases one -0 accompanies the ${ }^{+}-$pair, and in $35 \%$ of the cases the number of -0 's accomvanylng the $-_{-}^{-}$pair is more than one. In all the remaining cases, the number of charged pions 154 or more, with and without -o accompaniment. In the case of $\bar{n}$ annihilation, there will always be at least nne - ${ }^{+}$and the situation is more favorable. There are also processes involving $k$ meson emission, but we do not list them here because all of these together have a branching ratjo of only $4 \%$.

In practice the $\bar{n}$ annihilation will take place on a nuclear target. For this reason it is useful to consider the resulcs obtained fruii: a study of $750 \mathrm{Mel}$ antineutrnn annihilations in a heav liquid bubble chamber. [17] Although the chamber contained $22^{-}$by weight of $\mathrm{Br}$, this: accounted for only $10 \%$ of the annthilations. Most of the annibilatints took place in the light elements, $18 \%$ in $\mathrm{H}, 58 \%$ in $\mathrm{C}$, and 14 . in $\mathrm{F}$. Each annihilation gave, on average, $2.8- \pm, 1.2-{ }^{-}$and $2.1 p$. The rian kinetic energy of the pions was $\bar{E}_{-}=322 M \mathrm{M}$, but as is shom in Figure 3 the distribution peats below $100 \mathrm{MeV}$. An appreciablu arout of energy (and mumentum) goes to protons. The average energ: is $\bar{E}_{\mathrm{Y}}$ $=88 \mathrm{Mel}$. Most of the procons would be missed in all of the dutccurs proposed so far. These indications underline the importanct of uning che lightest possible element for the target.

\section{The $n-\bar{n}$ Experiments}

One $\mathrm{n}$ - $\bar{n}$ experiment has alré Jy beeri completed. It has carriod out at the Grenuble reactor $[18]$ and a report was given to this hurkshup last year. The experiment used one of the cold neutron beams that are avallable at Grenoble. The conditions of the experiment were very clean. The cold neutrons, with average velocity $150 \mathrm{~m} / \mathrm{s}$ are bent arnund a curved path by total reflection. They reach the detector virtually free of capture gammas and fast neutrons. The flux, 

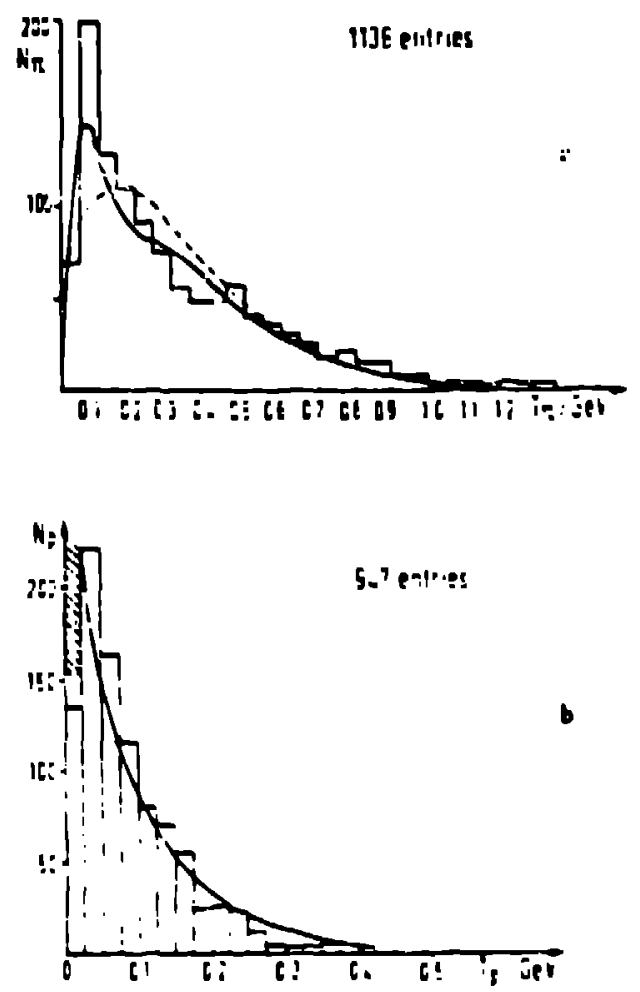

Figurc ? Kinetic energy distributions a) for plons and b) procons obtained using 750 Mel $\bar{n}$ in heavy liquid buoble char.ber. The events of the nip typa which were mainly on hydrogen were excluded from the pion plot. Solid lines: results from a model; dashed linc in pion spectrum: distribution for annthilations on frec nucleons.

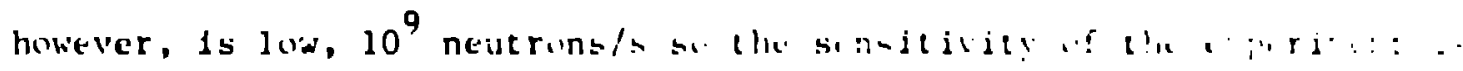

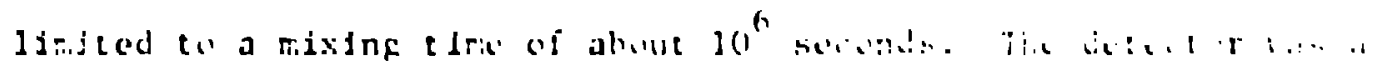

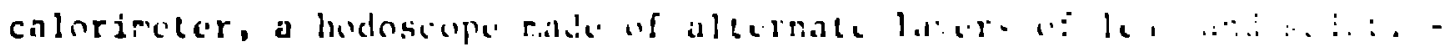

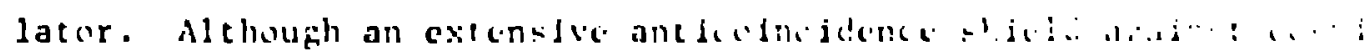

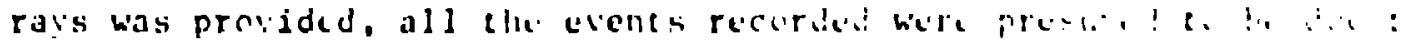

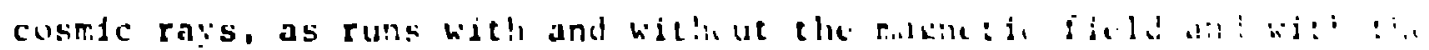

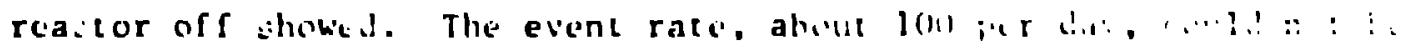

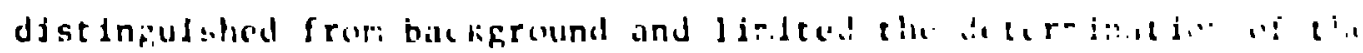

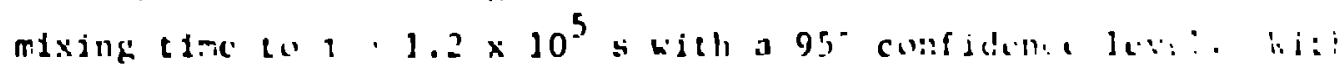

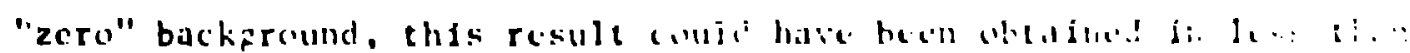

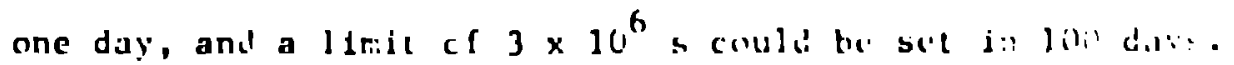

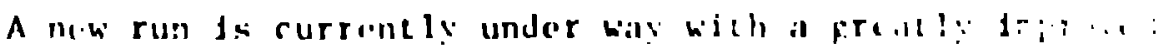

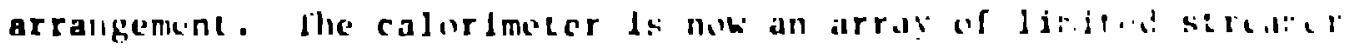

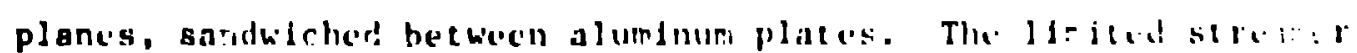

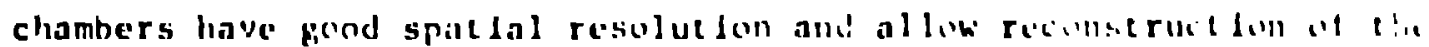
events to check that the". originate fron :he tarife. The limlta:

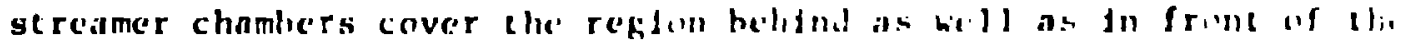

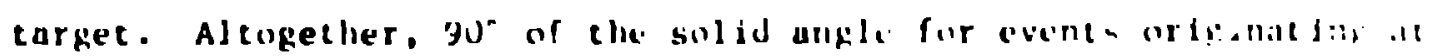
the target is covered. There are no resulte aciallable at this tinc. but the report is that the discrimination akifist the batk; rulu! hit:- 
been greatly 1mproved.

A sesond experiment is currently being mounted in Palia. [19] The neucron source is 6 Triga reactor. Alchough this reactor is only $250 \mathrm{kw}$, it is being adapted exclusively for this experiment. The full area of the thermal column is being utilized, together with a long flight path and a large target erea. As a tesult, a sensitivity $\tau=10^{7} \mathrm{~s}$ is anticipated even though the neutrons will be at room temperature anci not cooled.

The oiher experiments $(20)$ are all at the proposal stafic. Thic: a: mpt to explati neutron sources of higher intensity to critend the sensicluity beyond $10^{7} \mathrm{~s}$, possibly even somewhat abric $10^{8} \mathrm{~s}$. Thesc

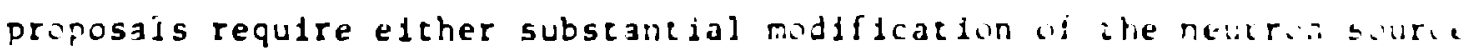
and/or a more elaborate detector. Thus, these experimellis, it tha: come off at all, are sone years down the roaj. In conslduring ticuir

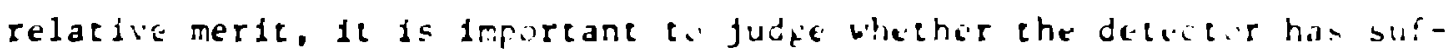

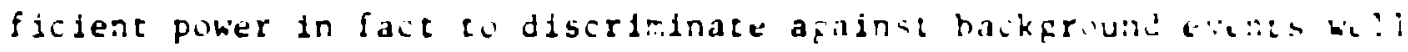

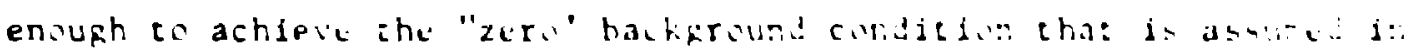
quiting sensitivit:

7. Detector "roblen

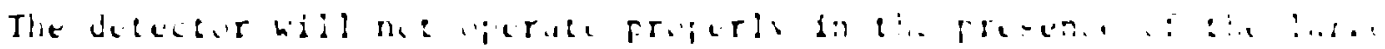

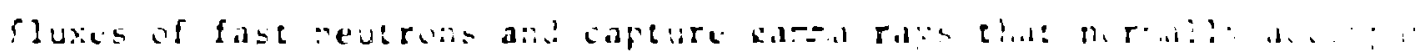

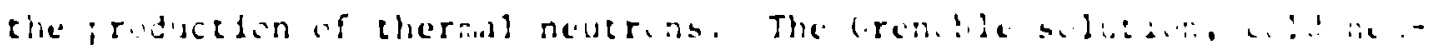

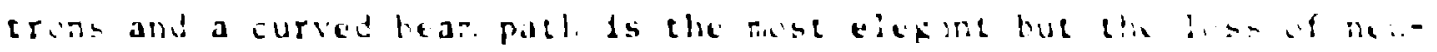

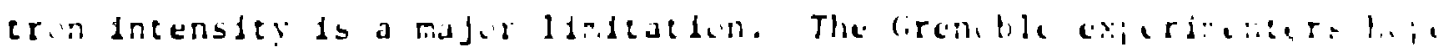

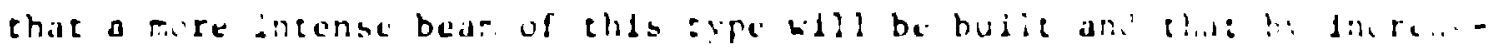

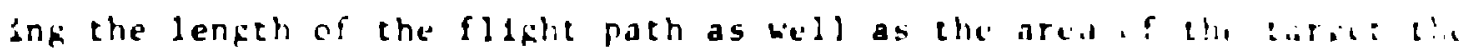

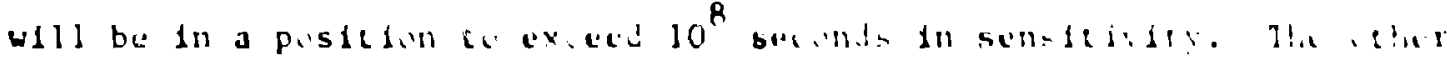

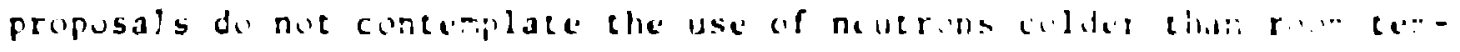

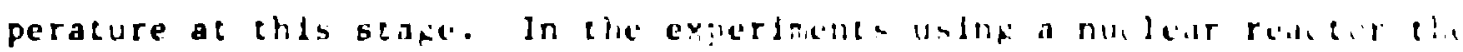
neutrons are extracted over a larpe area clene to the cire ant care fase

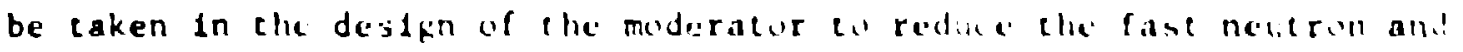
gamma ray fluxes that cone from the cure. This it dene by a sultable

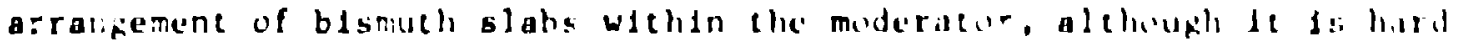
to do thls without some loss in thermal neutron entensley. It helph tw place the detector as far away from the renctor as possble, 1.e.. a long drift distance. It also helps to use a thin target through wildeh mobt of the neutruns and gama raye in the beam can pasb wlthuut 
Interacting unt1l they reach a beam stop far beycnd. The targct, of course, must be thick enough to stop any of the antineutrons which ria: have appeared in the beam. This leads to a detector in the form of a cylinder which surrounds the target and subtends as large a solid anit: around it as practical. Openings have to be left for the beam to cintur and leave, to enc up in the beam stop bejond. A series of baffles in the drift cube upstream of the detector is used t" collimate the bear., to make it strike the target but not the inside wall of the detectir around $1 t$.

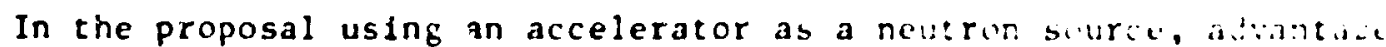
is taken of the pulsed beam. The time of flight ce far.a ra:t and fa-t neucrons doin the drift tubc in very different frow the slin theral

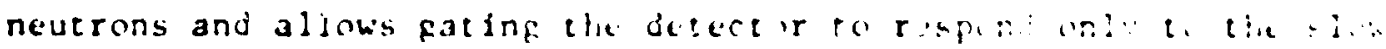
neusrons.

8. Costic kay Barkigrum!

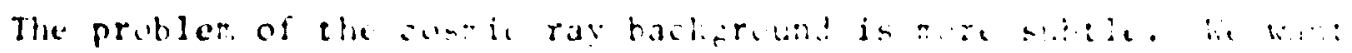

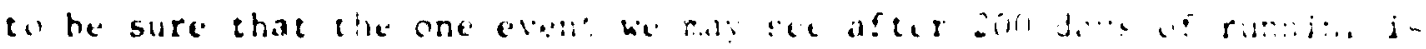

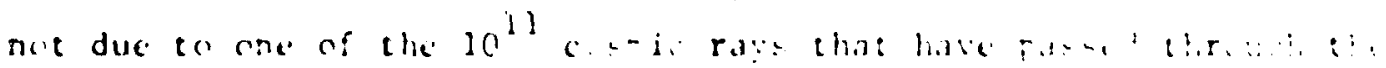

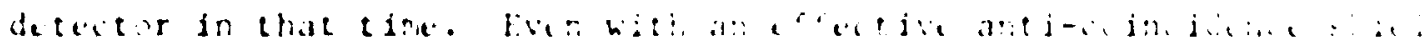

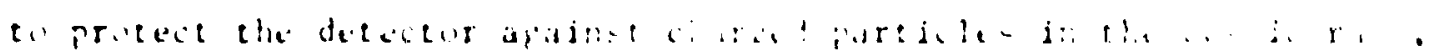

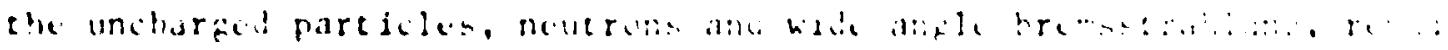

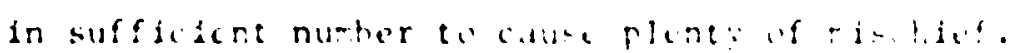

9. Detector (riecriat

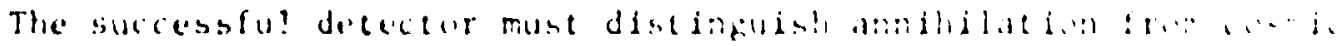

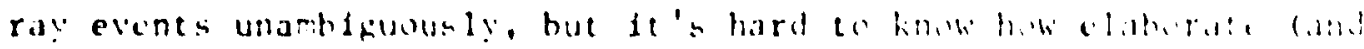

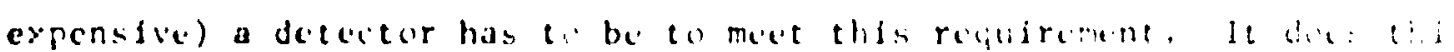

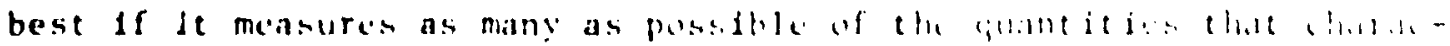
terize an annlhilat don event, Mancly:

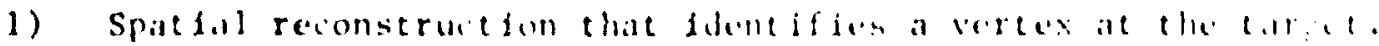

- Tempord reconstruction that show's the particles to be mivind from the vertex, not towird lt.

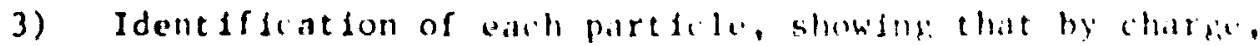
energy, and momeneum, it is a Jikely compenent of an amoihilation channel. 
4) The multiplicity is that of a probablc annihilation channcl.

5) The total energy is consistent with 2 Gol.

6) The total momentum is consistent with zero.

All deteciurs have limited space, time, energy, and momentur: resolution. In particular, since the annililation takes place in il nuclear target, not alj the energy can be made vistble, and some of the momentum will be caken up by nuclear recoll and reridin unseen. Bctar results can be obtained at greater cost by elaborating the detcecur. The problem is to know what is good enough. In this the pripintall differ.

he have already seen how, in the first cirenuble coicrirint, at. -

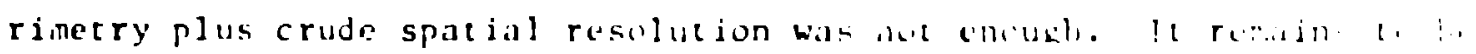

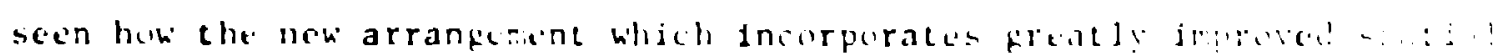

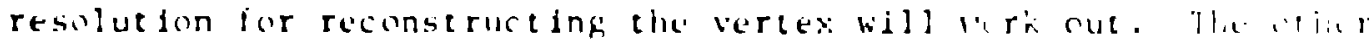
experdents deal with the probler in derferent wily...

10. Sumiary of n- $\bar{n}$ Priperimonts

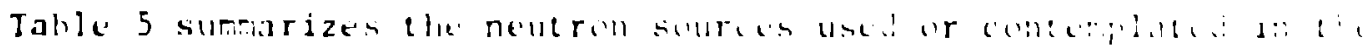

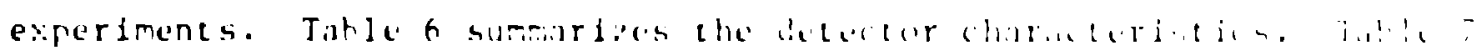

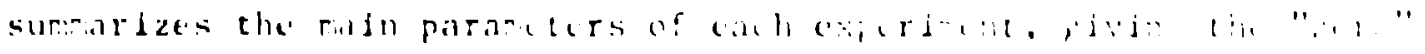

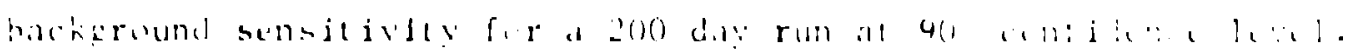

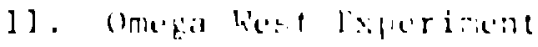

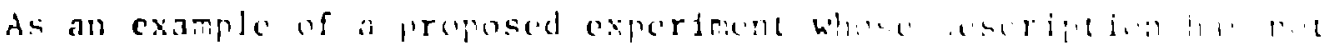

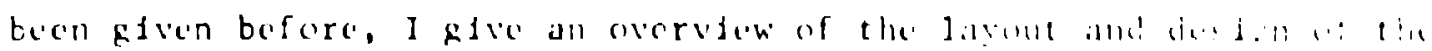

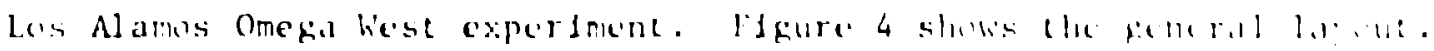

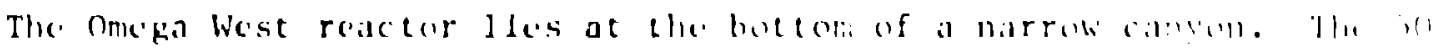

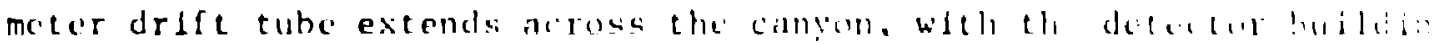

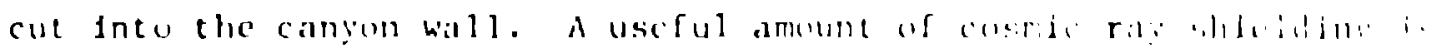

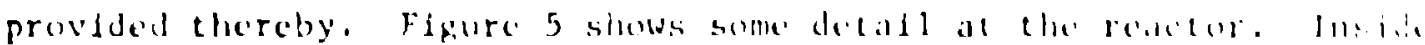

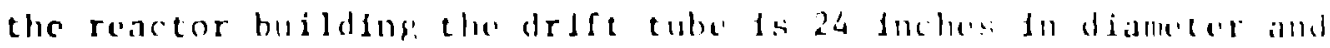

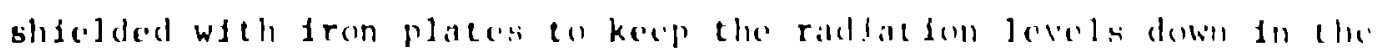

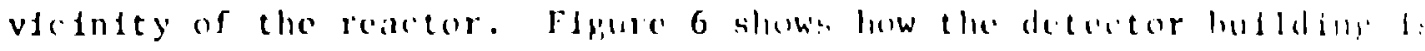

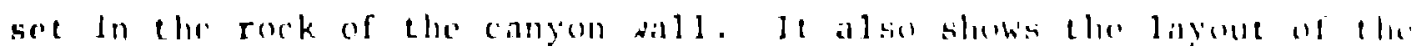

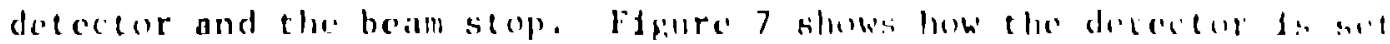

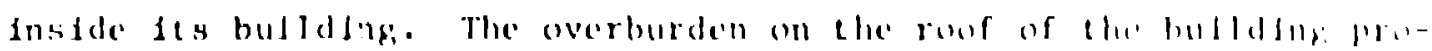

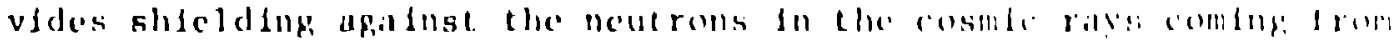


Table 5 Neutron Sources

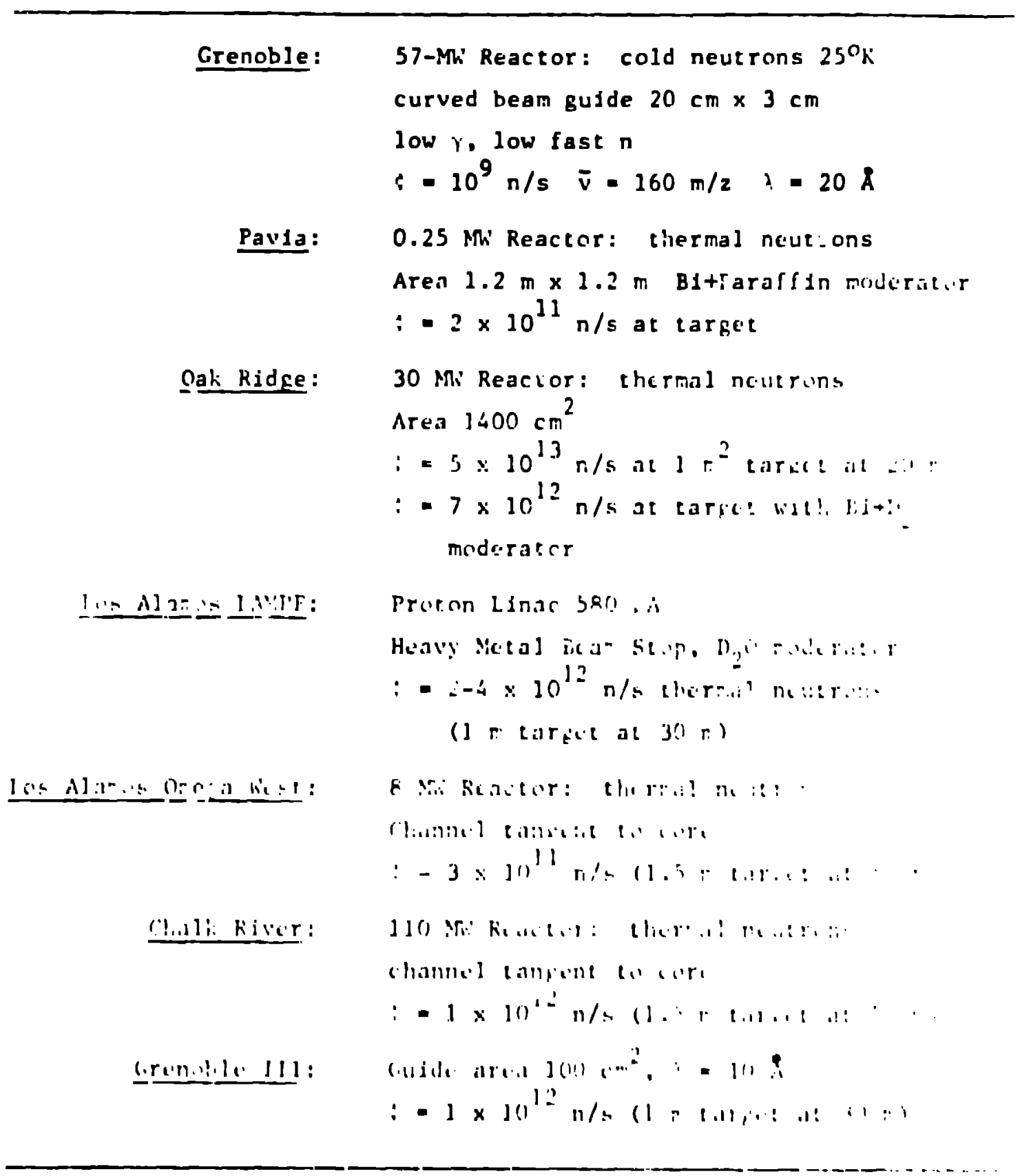

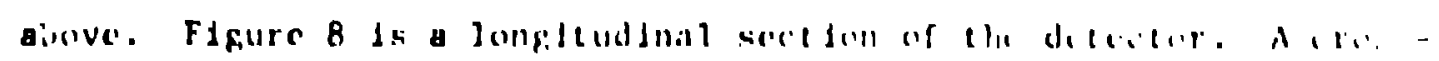

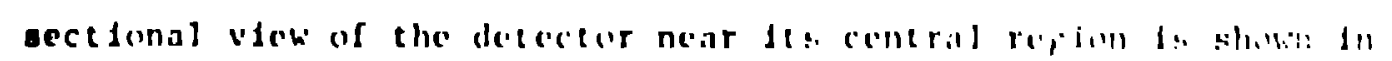

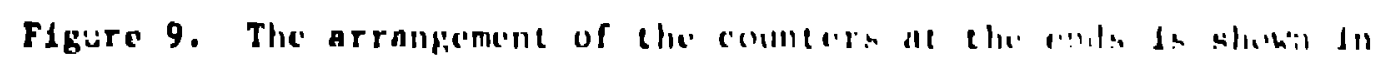

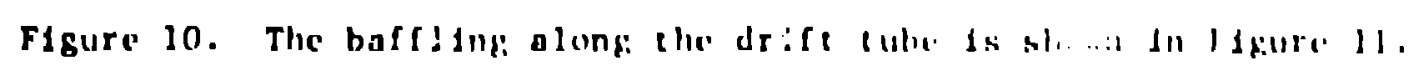

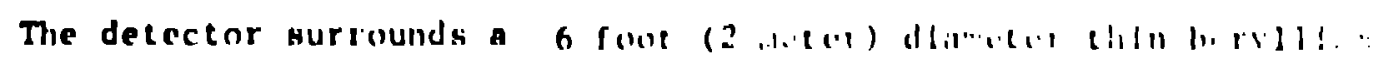

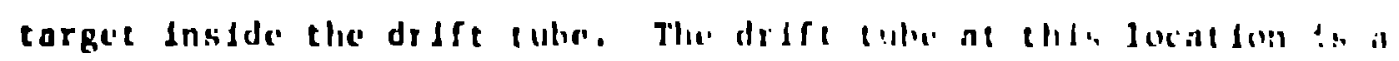

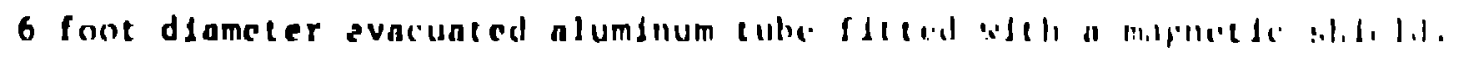

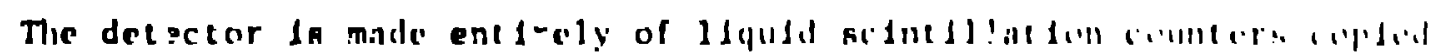

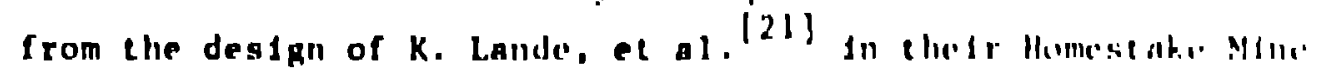


Table 6 Detectors

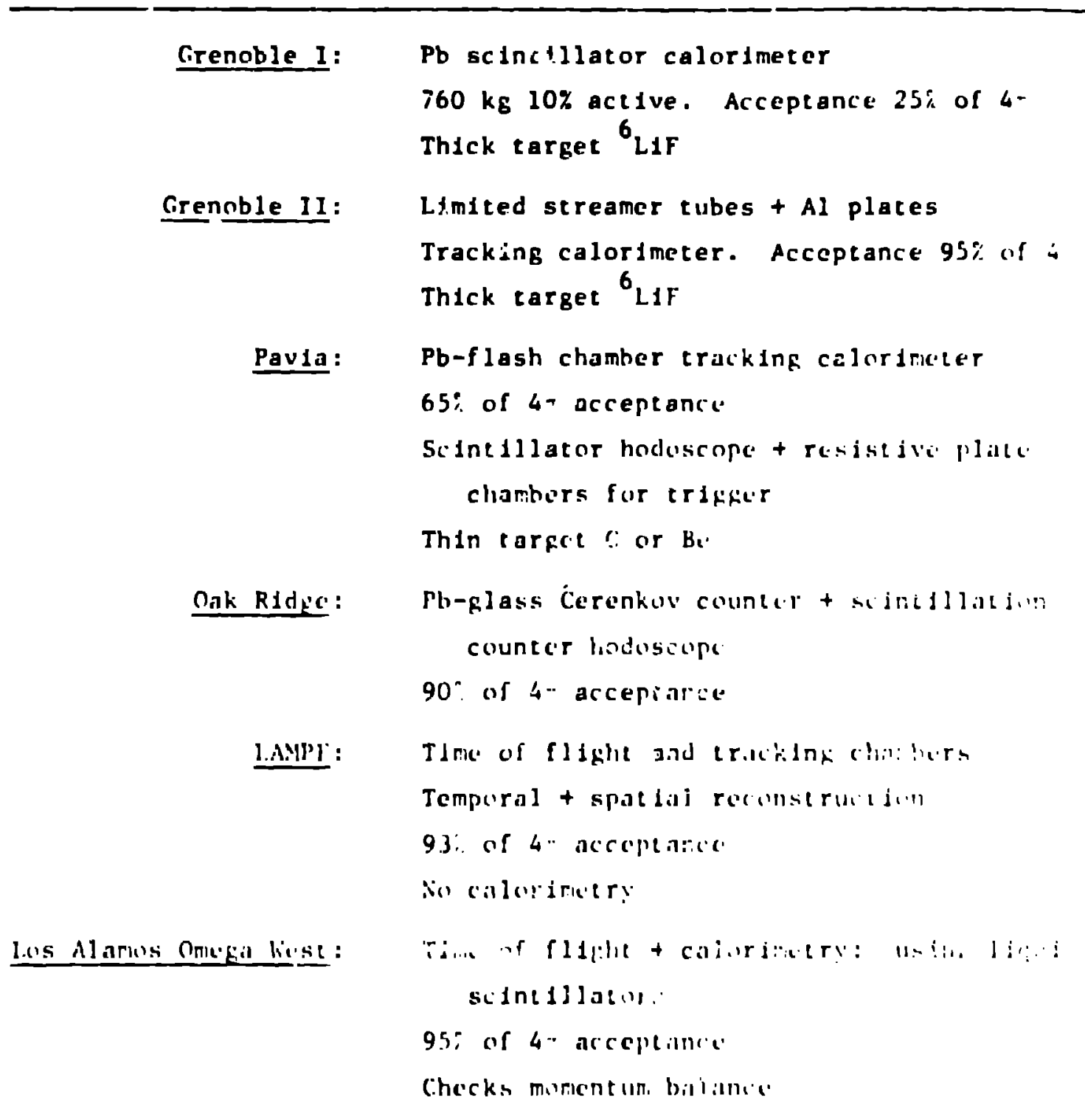

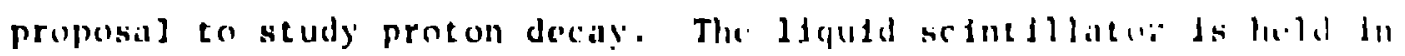

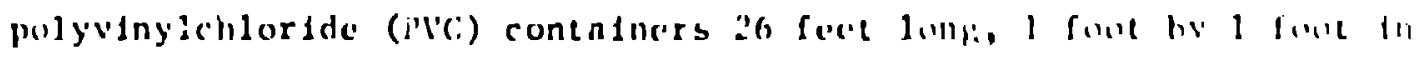

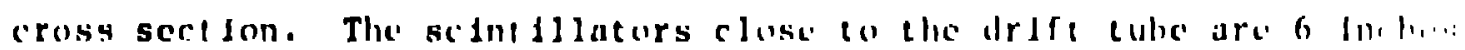

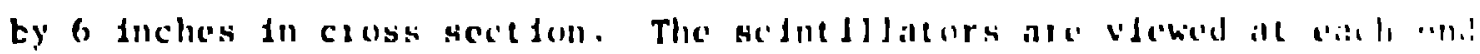

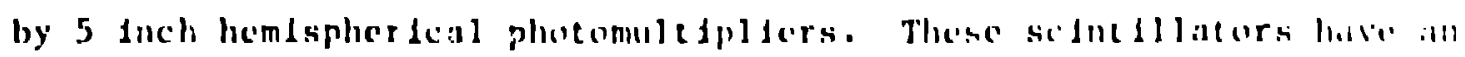

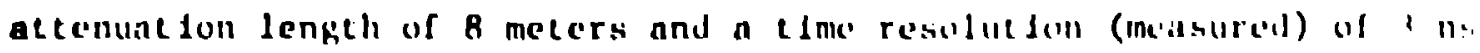

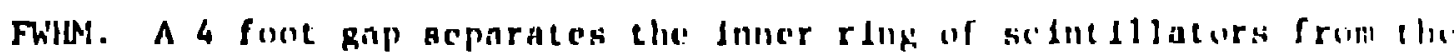

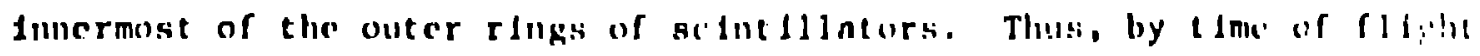

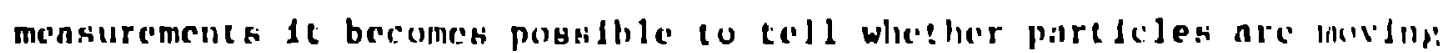

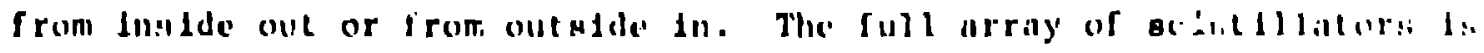

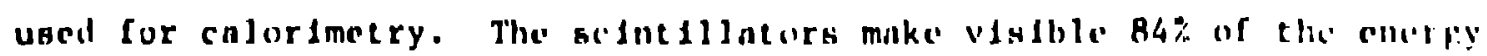

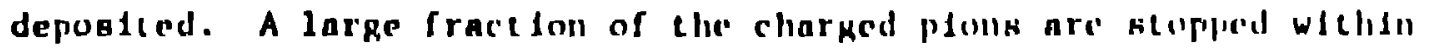


Tible 7 n . ñ Experiment

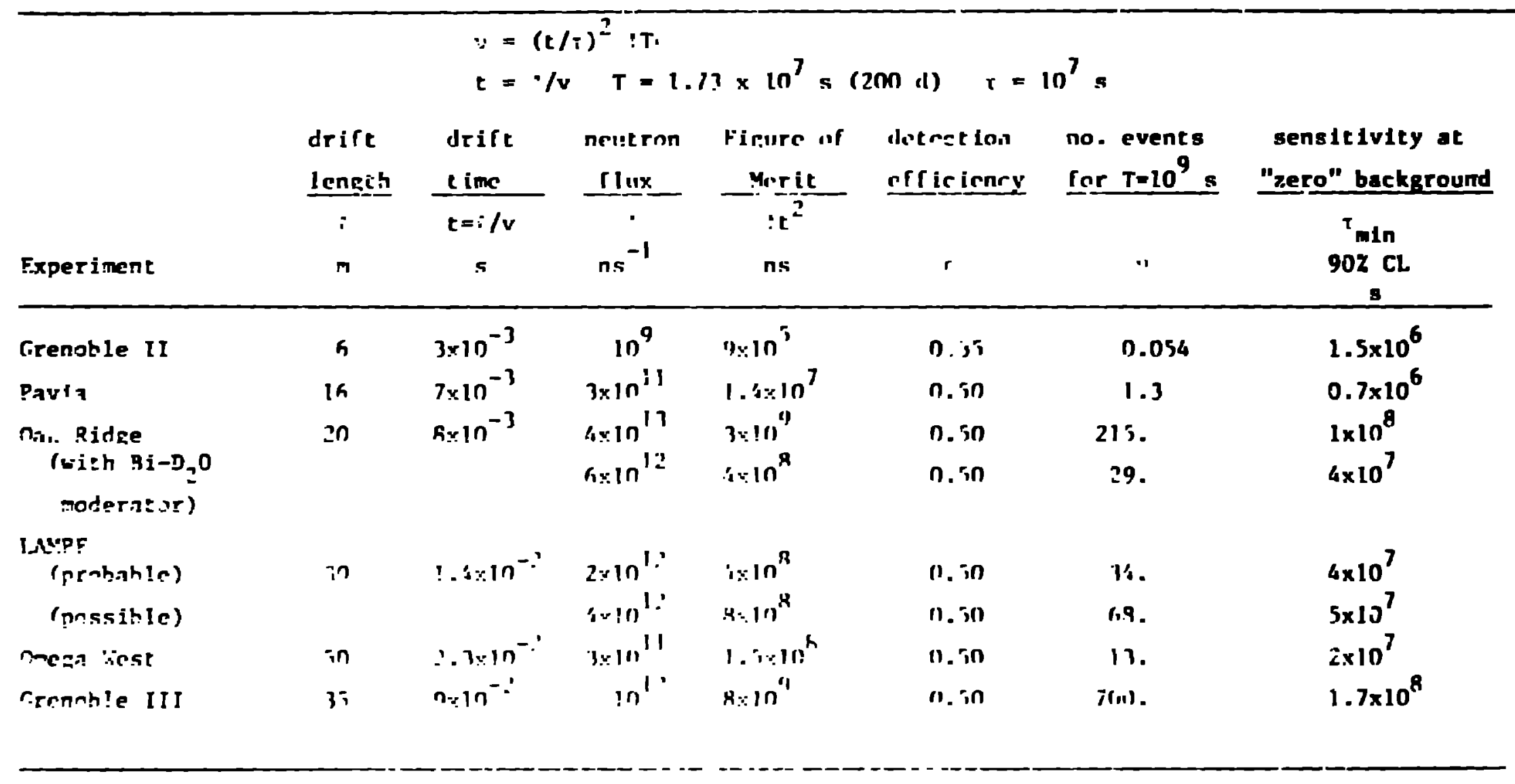




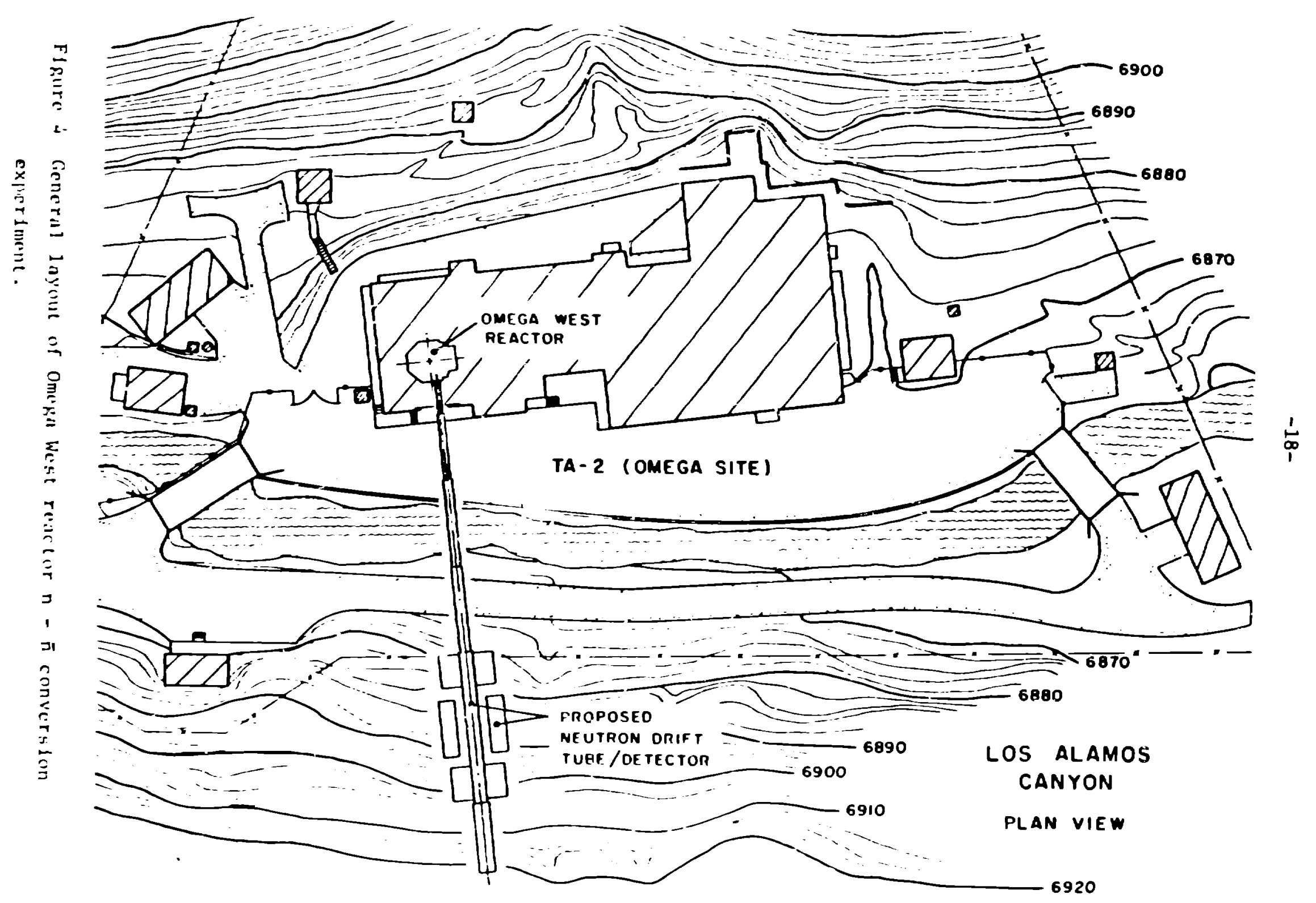




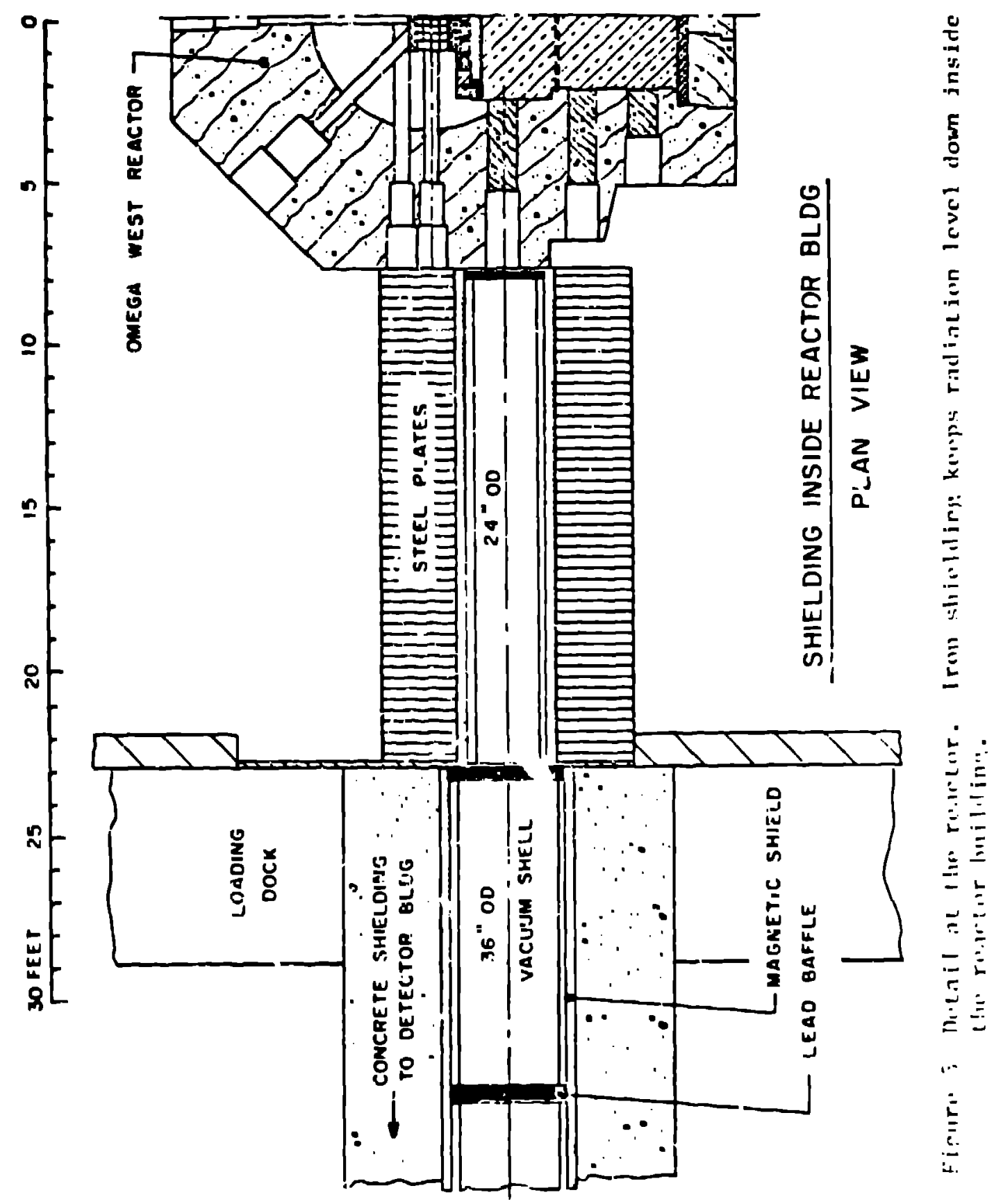

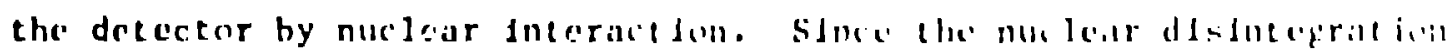
encrgy is recorded by liqude sedritllatur, the rest mass of the plail $j$ :-

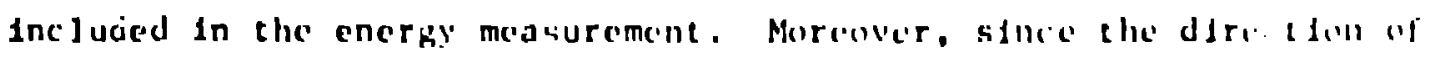

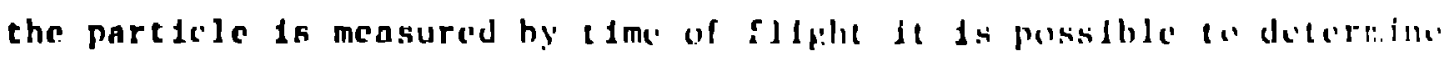
the mementum from the enerpy meisurement of eath of the particles thit

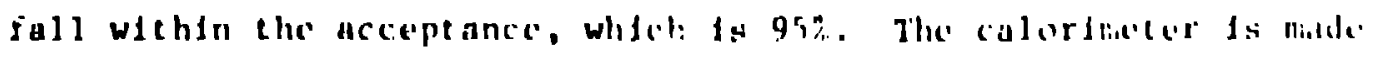

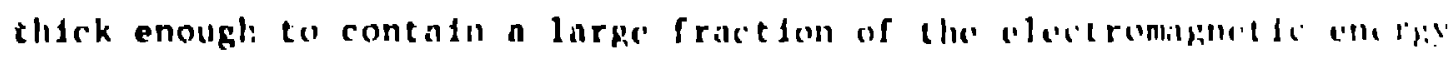




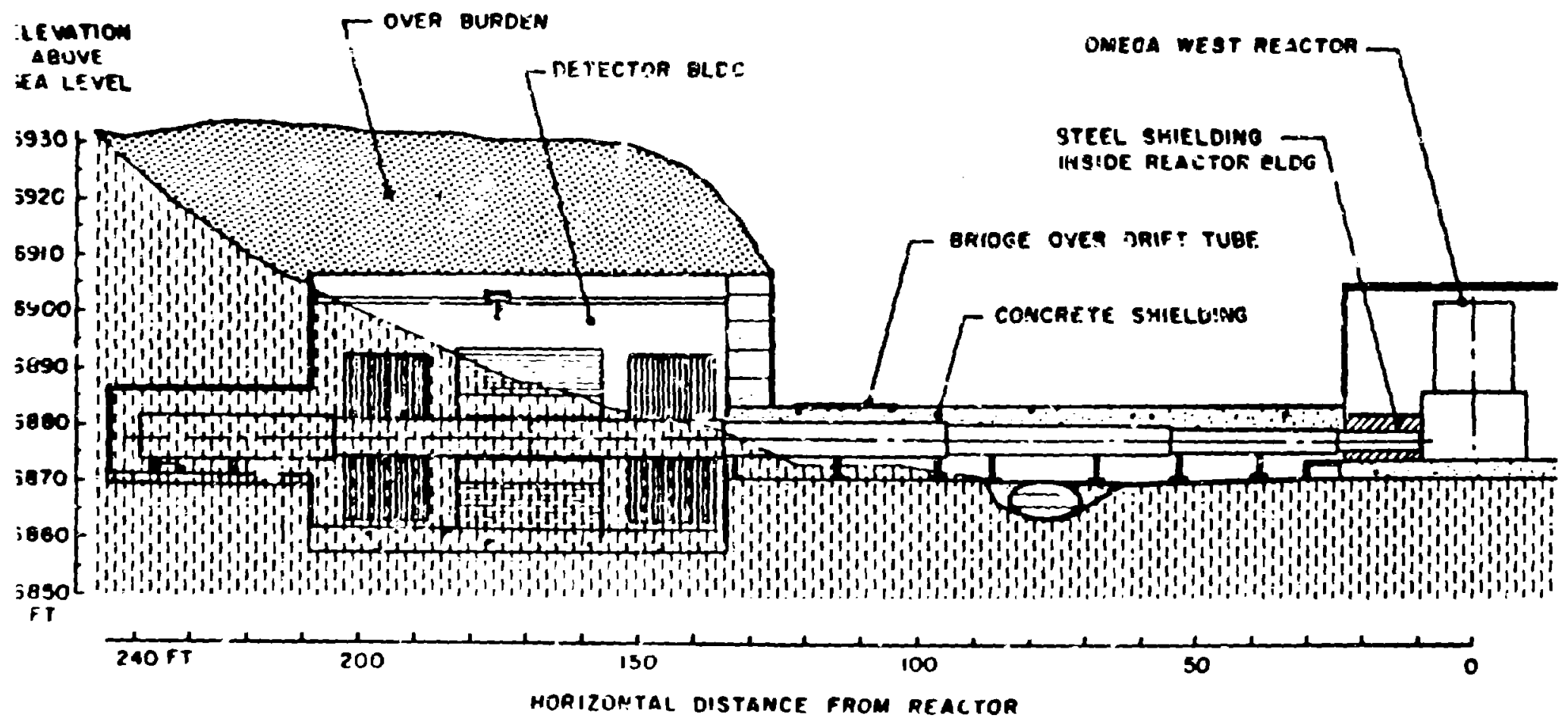

Finure o Detector hullding set in canson wall. 


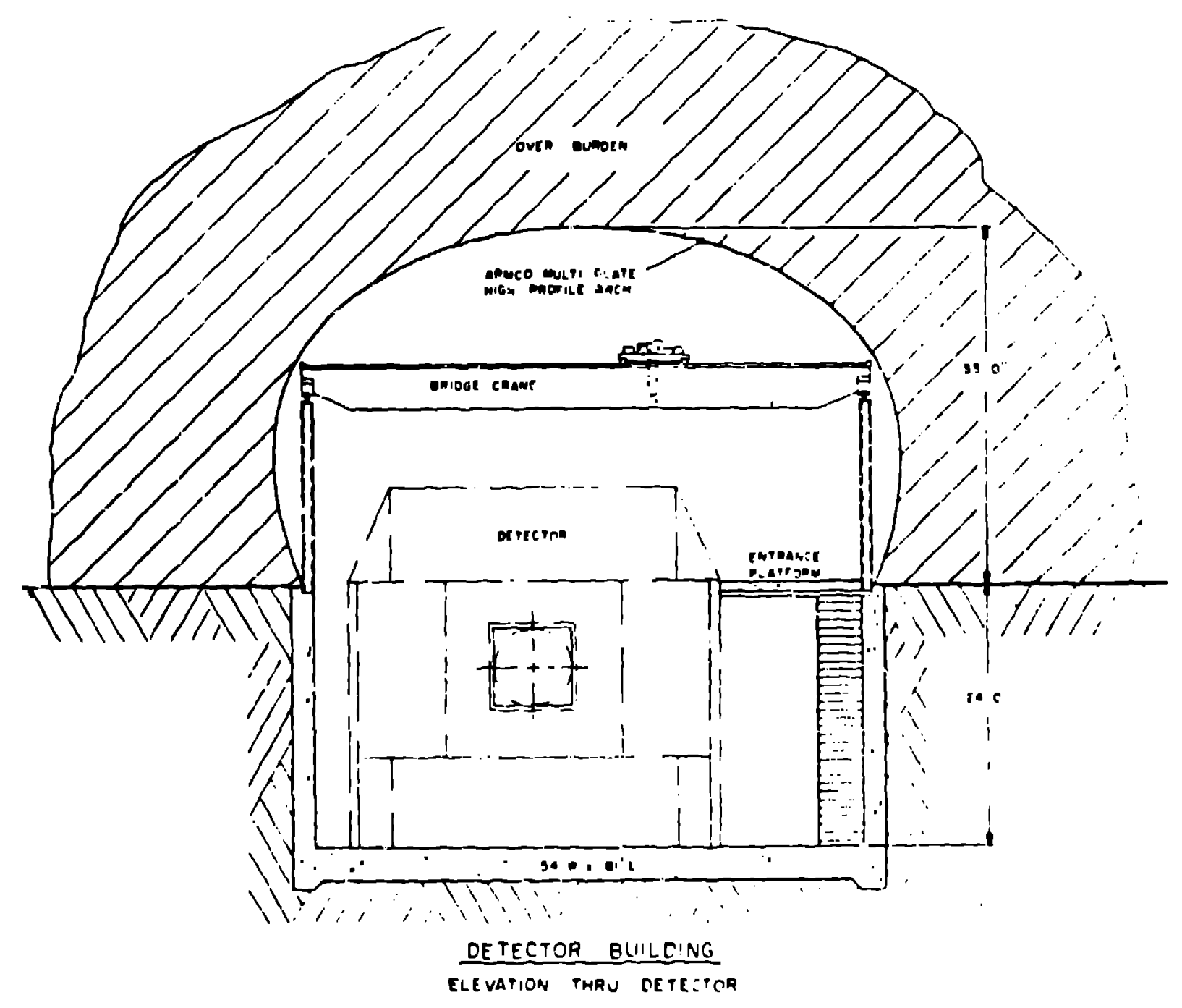

Figure 7 Detector bullding, cross-sectional view with the detector In place.

from the $\pi^{\circ} \mathrm{s}$. The scintillators are thick enough to provide a usiful means for discriminating against capture gamina rays. The encrgy deposited by lonization in $15 \mathrm{~cm}$ of scintillator is abole $27 \mathrm{Mel}$, much hlgher than the maximum posslble, $7 \mathrm{MeV}$, from the capture gamma rass. With a capture gamma ray flux $<10^{8} 5^{-1}$ enterling the detector, pile-up is not a sertous problem and a fimple discriminator at each pliutetule w11 make the detector rather Insensit ive to the capture gamma rays. The time of flight capability is used to vr:o cosmic ray events. 


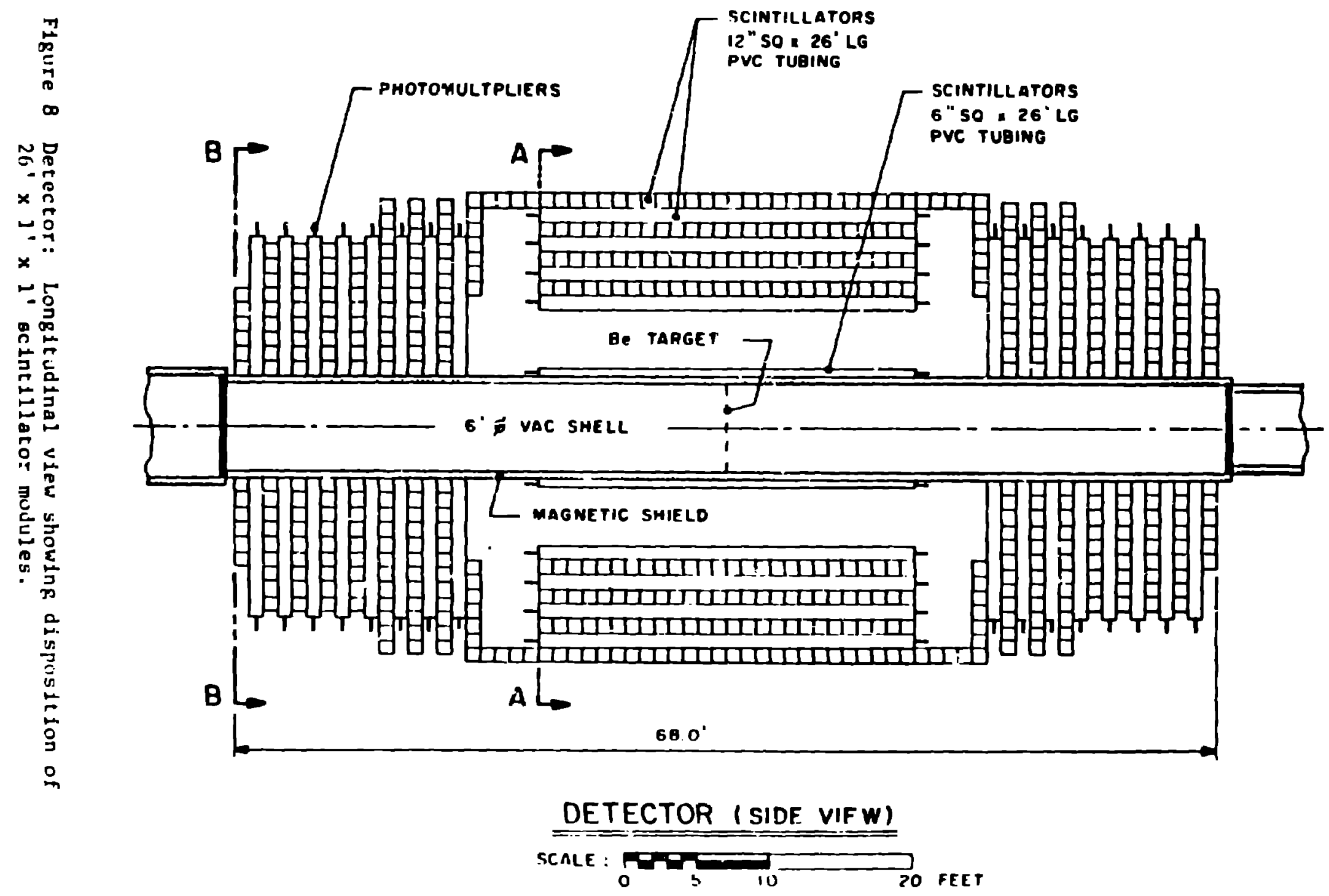




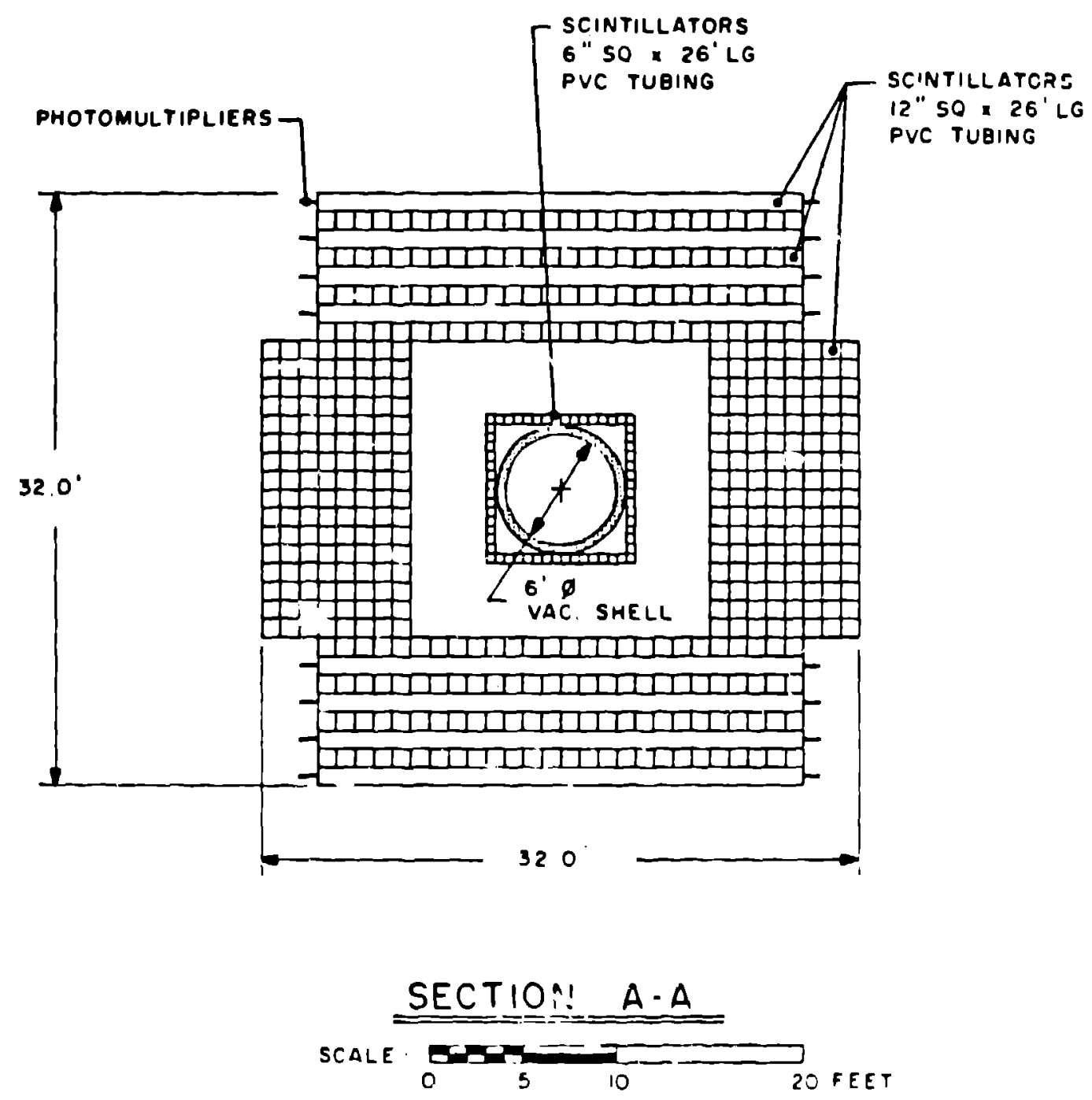

Figure 9 Cross-sectional vick of detector in central rogion.

A veto is provided whenever the time of flight measurorint clearly shows that there is a particle moving toward the Inside of the detcit.r. The spatial resolution of this detector, without the wse of chariter planes, $1 \mathrm{~s}$ about $30 \mathrm{~cm}$. Th1s should be suffictent to demonstrate hy spatial and temporal reconstruction that the event orieinates near the target and that energy and momentum balance as will as nultiplitits corresponds to what is probablu. from an annlhilation event. 


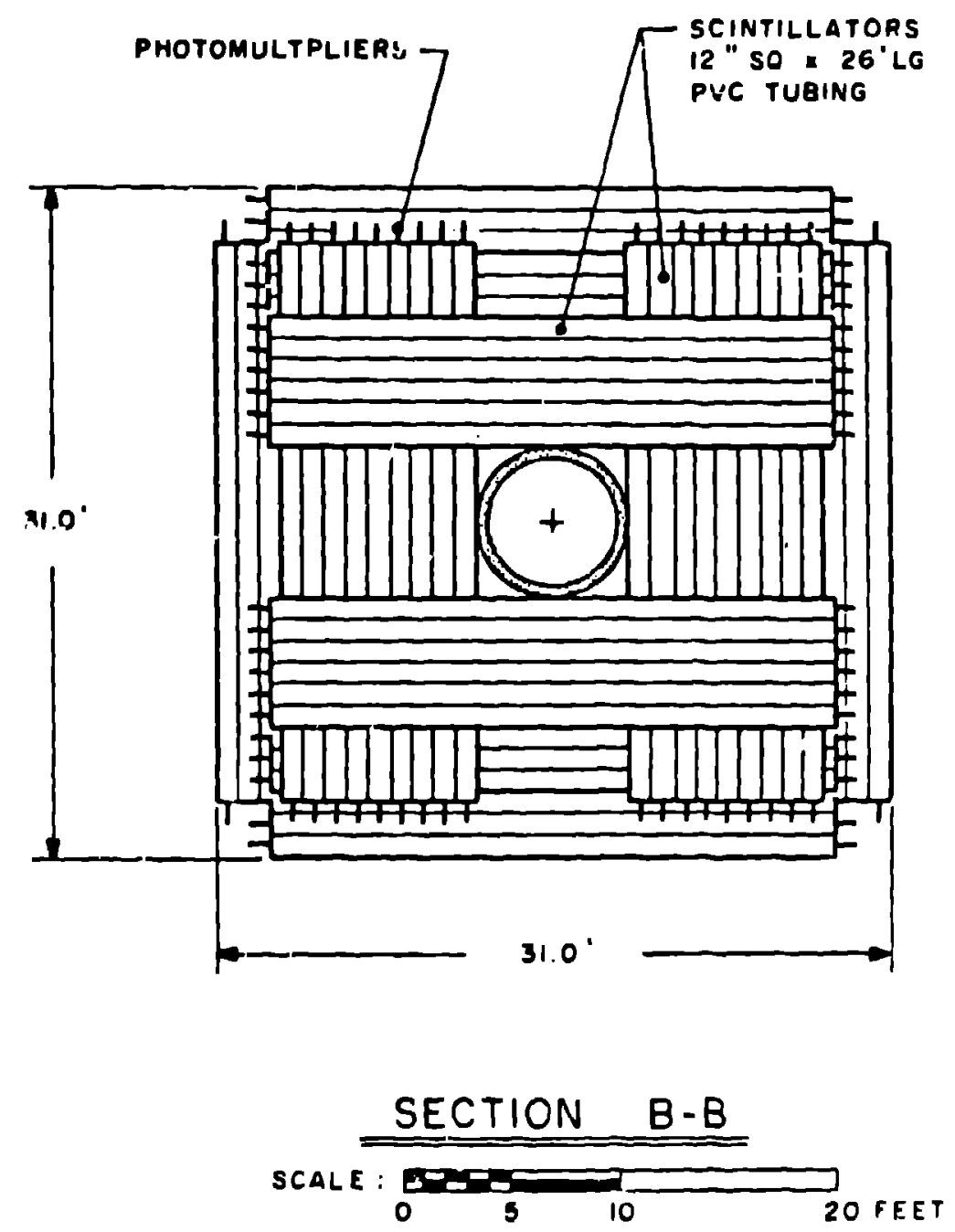

Figure 10 Cross-jectional view of end counters.

References

*Talk presented at the Third Workshop on Grand linification, T'le University of North Carolina, Chapel Hil1, NC, April 11-17, 198..

Los Alamos National Laboratory. Work performed under the auspices of the U.S.D.O.E.

[1] M. Gell-Mann and A. Pals, Phys. Rev. 97, 1387 (1955).

[2] v. A. Kuz'min, JETI Lett. 12, 228 (1970) [Origina]: Pis'nia Zh. Eksp. Teor. Fiz. 12, $335(\overline{19} 70)]$.

[3] S. L. Glashow, Harvard reports HUTO-79/A040, A059 (1979).

[4] J. Learned, F. Reines, and A, Son1, Phys. Rev. Lett. 43, 907 (1979).

[5] M. L. Cherry, M. Deakyne, K. Lande, C. K. Lee, R. I. Sténberg, and B. Cleveland, Ihys. Rev. Lett. 47, 1509 (1981).

[6] Y. Tosa and R. E. Marshak, VPI-HEP-B1/10. R. N. Mohapal ra anu 


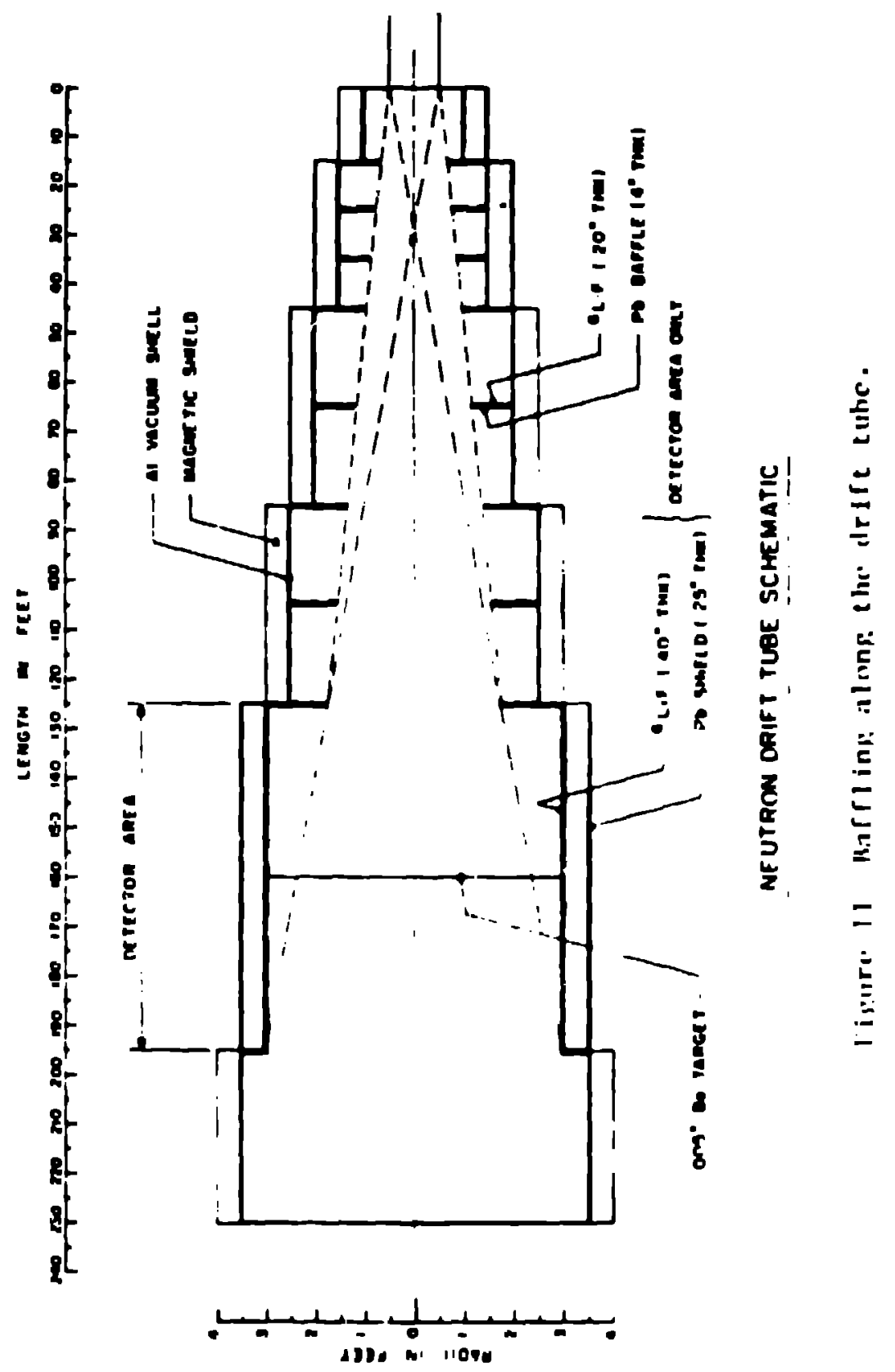

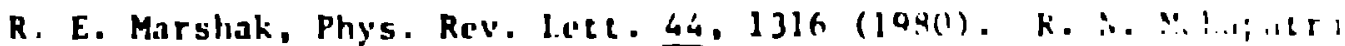

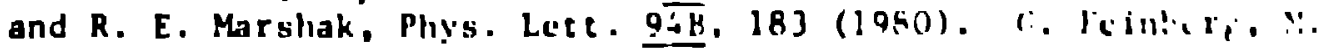

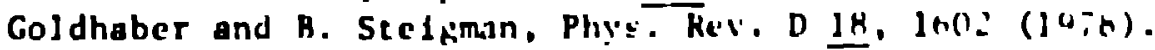

17] N. P. Chanf, In Proc. Workshop on heak Inecracticns as Prote: .; Unification, Blacksburli, la.. 1980 (dIP Conf. Proc. No. i2:

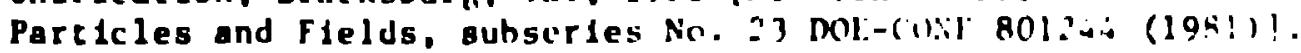

18] M. V. Kazainouski1, V. A. Kuz'mln, K. (.. Chezyahln, and M. I. Shaposhntkov, JeTp Lete. 32.82 (1980) forlginal: Pls mis :a!. Eksp. Tror. F12, 32, $88(\overline{1980)})$

(9) K. G. Chetyrkin, M. V. Kazarnovsk11, V. h. Kü'mln and Y. I. Shapoahnikov, Phys. Lett. 998. 358 (1981). 
[10] P. G. H. Sandars, J. Phys. C. (Nuclear Physics) E. L616 (1980).

[11] Riazzudin, Virginia Polytech. Inst. report, VPI-HE? $81 / 4$ (1981).

[12] L. N. Chang and N. P. Chang, Phys. Lett. 92B, 103 (1980); and Errata: Phys. Lett. 94B, 551 (1980).

[13] R. Cowsik and S. Nussinov. Univ. of Maryland, August 1980.

[14] ASTERIX collaboration proposal, "A Study of p̄p Interactions at Rest in a $\mathrm{H}_{2}$ Cas Target at LEAR". CERN/PSCC/80-101 PSCC/P28, August 29. 1980. See d lso, J. Diaz et al., Nucl. Phys. B16, 239 (1970), art references therein.

[15] A. Bettini et al., Il Nuovo C1mento 47A, 642 (1367).

[16] J. E. Enstrom, T. Ferbel, P. F. Slattery, B. L. werner, Z. C. I. Gulragossián, $Y$. Suml, and $T$. Yoshida, "N $N$ and $\bar{X} D$ Interactions-A Compllation", LBL-58, Berkeley (1972).

[17] H.-J. Besch, H. W. Elsermann, G. Nöldeke, W. Vollrath, D. Kaldren, H. Kowalsk1, H. -J. von Eyss, and H. von der Schmitt, 2. Physik A292, 197 (1979).

[18] G. Fidecaro, Neutrino '81 Conference on Neutrino Physics and Astrophysics, Mau1, Hawa11, July (1981). Milla Baldo-Ceolin, Proceedings of the $15 \mathrm{th}$ LAdPF lisers Croup Meeting, November ( 1981$)$. K. Green, Review of neutron-antineutron experiments, in Proc. 2nd Workshop on Grand Unification, Ann Arbor, Mich. (1981).

[19] S. Ratc1. Invited talk ICOBAN, Bombay, January 198?. ASDIK proposal [Pavia nucle-r reactor (1981)].

(20) R. bilson et al. (Harvard-Oak RIdge-Lnlv. Tennessec Collatiorallan). A sensit lve eearch for neutron-antineutron translitions, onf rescarcil proposal, 1981. K. LJ11s el al. ILos Alamis-lexas la : : -

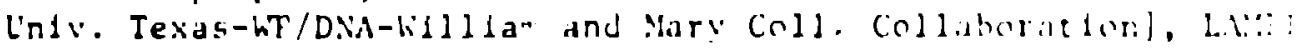
proposal Nio. fíi, rev. 22 June 1981.

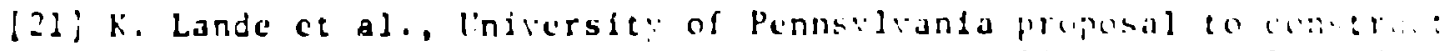

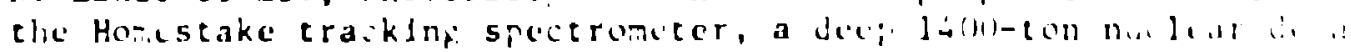
detector. September 1981. 